\title{
Immunoinformatics and Molecular Docking Studies Predicted Potential Multiepitope-Based Peptide Vaccine and Novel Compounds against Novel SARS-CoV-2 through Virtual Screening
}

\author{
Muhammad Waqas, ${ }^{1}$ Ali Haider, ${ }^{1}$ Abdur Rehman, ${ }^{1}$ Muhammad Qasim, ${ }^{1}$ Ahitsham Umar, \\ Muhammad Sufyan, ${ }^{1}$ Hafiza Nisha Akram, ${ }^{2}$ Asif Mir, ${ }^{3}$ Roha Razzaq, ${ }^{1}$ Danish Rasool, ${ }^{1}$ \\ Rana Adnan Tahir, ${ }^{4}$ and Sheikh Arslan Sehgal $\oplus^{1,5}$ \\ ${ }^{1}$ Department of Bioinformatics and Biotechnology, Government College University, Faisalabad, Pakistan \\ ${ }^{2}$ Department of Environmental Sciences, Quaid-e-Azam University, Islamabad, Pakistan \\ ${ }^{3}$ Department of Biological Sciences, International Islamic University, Islamabad, Pakistan \\ ${ }^{4}$ Department of Biosciences, COMSATS University, Sahiwal Campus, Islamabad, Pakistan \\ ${ }^{5}$ Department of Bioinformatics, University of Okara, Okara, Pakistan
}

Correspondence should be addressed to Sheikh Arslan Sehgal; arslansehgal@yahoo.com

Received 14 April 2020; Revised 13 August 2020; Accepted 8 February 2021; Published 26 February 2021

Academic Editor: Burak Durmaz

Copyright (c) 2021 Muhammad Waqas et al. This is an open access article distributed under the Creative Commons Attribution License, which permits unrestricted use, distribution, and reproduction in any medium, provided the original work is properly cited.

\begin{abstract}
Background. Coronaviruses (CoVs) are enveloped positive-strand RNA viruses which have club-like spikes at the surface with a unique replication process. Coronaviruses are categorized as major pathogenic viruses causing a variety of diseases in birds and mammals including humans (lethal respiratory dysfunctions). Nowadays, a new strain of coronaviruses is identified and named as SARS-CoV-2. Multiple cases of SARS-CoV-2 attacks are being reported all over the world. SARS-CoV-2 showed high death rate; however, no specific treatment is available against SARS-CoV-2. Methods. In the current study, immunoinformatics approaches were employed to predict the antigenic epitopes against SARS-CoV-2 for the development of the coronavirus vaccine. Cytotoxic T-lymphocyte and B-cell epitopes were predicted for SARS-CoV-2 coronavirus protein. Multiple sequence alignment of three genomes (SARS-CoV, MERS-CoV, and SARS-CoV-2) was used to conserved binding domain analysis. Results. The docking complexes of 4 CTL epitopes with antigenic sites were analyzed followed by binding affinity and binding interaction analyses of top-ranked predicted peptides with MHC-I HLA molecule. The molecular docking (Food and Drug Regulatory Authority library) was performed, and four compounds exhibiting least binding energy were identified. The designed epitopes lead to the molecular docking against MHC-I, and interactional analyses of the selected docked complexes were investigated. In conclusion, four CTL epitopes (GTDLEGNFY, TVNVLAWLY, GSVGFNIDY, and QTFSVLACY) and four FDA-scrutinized compounds exhibited potential targets as peptide vaccines and potential biomolecules against deadly SARSCoV-2, respectively. A multiepitope vaccine was also designed from different epitopes of coronavirus proteins joined by linkers and led by an adjuvant. Conclusion. Our investigations predicted epitopes and the reported molecules that may have the potential to inhibit the SARS-CoV-2 virus. These findings can be a step towards the development of a peptide-based vaccine or natural compound drug target against SARS-CoV-2.
\end{abstract}

\section{Background}

There are a variety of human diseases with unknown etiology. A viral parentage has been purposed for numerous diseases and also has significance to search new viruses [1].
Various difficulties have been faced which scrutinize new viruses, such as some viruses do not replicate in vitro and have cytopathic effects (CPE). The viruses that are unable to replicate in vitro leads to the failure of virus discovery. The DNA-amplified restriction fragment length polymorphism 
(cDNA-AFLP 4) technique helps to identify the new viruses including the discovery of new coronavirus [1].

Coronaviruses, a genus of the Coronaviridae family, are enveloped viruses recognized as of large plus RNA strand genome. The size of RNA is $27-32 \mathrm{~kb}$ and polyadenylated. There are three groups of coronaviruses that are serologically distinct. Viruses are characterized within each group by their genomic sequence and host range [2]. Coronaviruses have been discovered in mice, turkeys, cats, horse, and humans and cause many diseases including respiratory tract and gastroenteritis [2].

Two human viruses (HCoV-229E, HCoV-OC43) were identified in the mid-1960s and are known to cause the common cold. The recently identified SARS-CoV can cause a lifethreatening pneumonia and is the most pathogenic human coronaviruses identified thus far [3]. SARS-CoV is probable to occupy in animal source and recently initiated the epidemic in humans through zoonotic transmission [4]. SARS-CoV is the first membrane of a fourth group of coronaviruses [5].

In Wuhan (Hubei province, China), multiple patients associated to Hunan south China seafood market diagnosed with third zoonotic human coronavirus (CoV) of the century emerged in 31st of December 2019. CoV is similar to severe acute respiratory syndrome coronavirus (SARS-CoV) and Middle East respiratory syndrome coronavirus (MERS$\mathrm{CoV}$ ) infections including fever, lung infiltration, and difficulty breathing [6]. After an extensive speculation about the causative agent of $\mathrm{CoV}$, the identification of novel $\mathrm{CoV}$ was announced by the Chinese Center for Disease Control (CDS) on 19th of January 2020 [7]. The novel CoV, SARS$\mathrm{CoV}-2$, was insulated from a single patient and later corroborated from 16 more patients [8]. The viral pneumonia of SARS-CoV-2 was quickly predicted as the likely causative agent, while not yet confirmed.

The first sequence of SARS-CoV-2 has been submitted after its conformation [9]. Later, five more sequences of SARS-CoV-2 were deposited to the GSAID database on 11th of January from Chinese institutes [10] (Supplementary 1); multiple sequence alignment of SARS-CoV, MERS-CoV, and SARS-CoV-2 carried out and conserved part in DNA, as well as protein sequence, was observed. Hundreds of human deaths were linked with infection having significant morbidities with the age $>50$. Various clinical symptoms have been highlighted such as dry cough, leukopenia, fever, and shortness of breath. The extracorporeal membrane oxygenation of the patients considered severe cases and need supportive care. The infection of SARS-CoV-2 in elderly patients are less virulent as compared to SARS-CoV $(10 \%$ mortality) and MERS-CoV (35\% mortality) [11].

1.1. Origin. The source of the SARS-CoV-2 is still unclear, although the initial cases have been associated with the Huanan South China Seafood Market. The early patients present in the Market got the virus through either human-to-human transmission or a more widespread animal source [11].

The samples from the infected market showed positive results for the novel coronavirus while no specific animal association has been identified [12]. Through codon analyses, it is suggested that the snakes might be the possible source of the viral infection [13], although the assertion has been disputed by others [14] including possible animal vectors, and the researchers are trying to discover the source of SARSCoV-2.

Coronavirus was thought to infect humans and bats more effectively as both are more related to Coronavirus lifecycle [15]. It has been evidenced that several bats are capable of infecting human cells without intermediate adaptation [16]. The human serology data shows the association of bat $\mathrm{CoV}$ proteins leads to zoonotic transmission of SARS-like bat coronavirus for deadliest out breaks [17]. MERS-CoV is also a zoonotic virus and have the origin from the bats [18]. The zoonotic contacts of camel has been evidenced in primary cases of MERS-CoV [19]. These lessons from SARS and MERS highlight the importance of rapidly finding source for SARS-CoV-2 in order to stem the ongoing outbreak [19].

1.2. Susceptible Populations. With low patient data, who may be most sensitive to SARS-CoV-2 is difficult to make robust resolution. Disease severity such as SARS-CoV and MERS$\mathrm{CoV}$ equated strongly to host the condition including biological sex, age, and the overall health [20], and similar findings have been observed in early patients of SARS-CoV-2. The SARS- and MERS-CoV infection leads to increase the severity and death rate in people over the age of 50 years [21]. The observed patients having novel $\mathrm{CoV}$ had poor health conditions including diabetes, kidney or heart function issues, and hypertension that make them more susceptible for MERS-CoV outbreak, while diabetes, smoking, cardiovascular disease, hypertension, and other chronic illness have also been observed. In the majority of deaths and corresponding to findings in animal models [22], the results indicate that vigilance is essential for these weak patients following SARS-CoV-2 infection [22].

1.3. Insights from the Sequence. Dr. Zhang's group at Fudan University and many other groups in China instance the dedication and increased the capacity of the scientific infrastructures in China by rapid sequencing of nearly 30,000 nucleotide of the (COVID) genome [23]. The whole genome analyses of SARS-CoV-2 showed $\sim 80 \%$ nucleotide identity to the original SARS epidemic virus. The two different bat SARS-like CoVs (ZC45 and ZXC21) shared 89\% identity with the genome of SARS-CoV-2 [24]. It has been observed that the novel $\mathrm{CoV}$ showed recombination with previously identified bat coronaviruses through phylogenetic analyses [25]. A CoV sequence of bat (RaTG3) having 92\% sequence identity with the novel virus supports the bat origins for the SARS-CoV-2 [14].

The SARS-CoV-2 spike protein has roughly $75 \%$ amino acid identity with SARS-CoV [26] while the SARS-CoV-2 receptor-binding domain $(\mathrm{RBD})$ is $73 \%$ conserved with spike $\mathrm{RBD}$ of SARS-CoV by narrowing analysis relative to the epidemic RBD [27]. The receptor-binding domain of SARSCoV-2 was capable of binding with ACE2 in the context of the SARS-CoV spike protein [28].

1.4. Genomic Features and Lifecycle of the Coronavirus. Coronaviruses have unique club-like spikes, and the RNA 
genome is larger than other virus which leads to a unique mode of replication. Coronaviruses contain $\sim 30 \mathrm{~kb}$ of positive-strand RNA genome [29]. The significant features of coronavirus genomes include a $5^{\prime}$ caped end which plays an important role in the replication of RNA, as $5^{\prime}$ end has a leader sequence along with a UTR region, possessing essential loops. The 3 ' poly-A tail end has essential structures for RNA genome synthesis and replication [30]. These two modifications allow RNA viruses for translation of replication (replicase) proteins [23].

A coronavirus genome has significant parts and helps for the synthesis and replications of whole genome (Figure 1) [31].

The conformed cases of virus have been confirmed by 25 countries [32-34] Tables 1 and 2 (Supplementary 1).

Our current study is aimed at exploring and identifying potential B- and T-cell epitopes through immunoinformatics approaches which help to design effective vaccine against deadly SARS-CoV-2. In addition, the study is aimed at pointing out specific peptides from coronaviral proteome, which have ability to bind with major histocompatibility complex (MHC), one of the most crucial step in vaccine designing. Different bioinformatics tools are applied to follow immunoinformatics approach.

\section{Methods}

2.1. SARS-CoV-2 Sequence Retrieval. The primary amino acid sequence of coronavirus protein was extracted from the crystal structure of SARS-CoV-2 main protease in complex with an inhibitor N3 from Protein Data Bank (PDB ID: 6LU7) [35]. The individual sequence length of corona viral protein was 306 amino acids from the genome polyprotein, and a three-dimensional (3D) structure was determined by X-ray diffraction having $2.16 \AA$ resolution. The physiochemical properties of the selected protein were evaluated by using ProtParam [36].

2.2. Multiple Sequence Alignment (MSA). MSA is performed on all three full-length genomes (SARS-CoV = NC_004718, MERS-CoV = NC_019843.3, and SARS-CoV-2 = NC_ 045512.2), all genomic sequences taken by GenBank [37, 38] and multiple sequence alignment carried out by Clustal Omega $[39,40]$. The conserved parts were labeled by using WebLogo3 [41].

2.3. Conformational and Linear B-Cell Epitopes Prediction. The interaction of the antigen B-cell epitope with Blymphocyte classifies the B-lymphocytes to differentiate into the two types of cells as memory cells and antibody-secreting plasma [42]. The accessibility and hydrophilic nature were considered the key features of the B-cell [43] by accessing the immune epitope database and analysis resource (IEDB) (http://www.iedb.org/) as stated by flexibility prediction of Karplus and Schulz [44], hydrophilicity prediction of Parker et al. [43], antigenicity scale of Kolaskar and Tongaonkar [45], and Emini et al. surface accessibility prediction [46]. The conformational B-cell epitopes were predicted by employing ElliPro (http://tools.immuneepitope.org/
toolsElliPro/) [46] from the IEDB analysis resource. This analysis resource incorporates three diverse algorithms comprising protein shape approximation [47], residues protrusion index (pI) [48], and the adjacent residue clustering based on $\mathrm{pI}$.

\subsection{Potential Cytotoxic T-Lymphocyte (CTL) Epitopes} Prediction. CTL epitopes were predicted by employing the NetCTL.1.2 server [49]. MHC molecules act as an antigen and utilize their surface to activate the CTLs. The NetCTL.1.2 server was employed to integrate the proteasomal C-terminal cleavage, MHC class I binding prediction, and transporter associated with antigen processing (TAP) transport efficiency. The sequences of the organism in FASTA format were submitted to the server, and afterwards, peptide lengths and human leukocyte antigen (HLA) alleles were selected and observed. Additionally, the T-cell epitope prediction and weight matrix algorithm were used for the TAP transport efficiency prediction, and artificial neural network was implemented to predict the proteasomal C-terminal cleavage and MHC class-I binding.

2.5. World Population Coverage Analysis. The world population coverage analysis was performed by utilizing IEDB server by utilizing the selected CTL epitopes which were searched against respective allele sets, and major world populations were covered by this analysis. The key purpose for this coverage analyses were to analyze whether the selected candidates were suitable for major populations or not. The analyses were performed against China, Iran, Japan, Korea, and some other countries which were being affected by the coronavirus in 2020 viral outbreak [50].

2.6. Peptide-MHC Protein Complex and Molecular Docking Studies. The predicted CTL epitope peptides of SARS-CoV2 with antigenic residues were selected for the molecular docking analyses. The PEP-FOLD3 server [51] was employed to model the 3D structures of the selected peptides with 200 simulation runs to sample the conformations. The conformational models clustered by PEP-FOLD3 server were evaluated on the basis of sOPEP energy scores [52]. Afterwards, the peptides with higher scores were selected for molecular docking experiments with MHC class I binding molecule comprising HLA-B (PDB ID: 3VCL) through the PatchDock docking server [53]. All the docked complexes which showed the undesirable penetrations of the receptor's atoms into the ligand were rejected, and the geometric shape complementarity score was applied to classify the other complexes. Subsequently, the FireDock server $[54,55]$ was utilized to refine the docked complexes and also predict the score of the docking outputs.

The FireDock server supports to rectify the scoring and flexibility issues generated during the docking calculations by fast rigid-body docking tools [56]. The molecular visualization programs PyMOL [45] (Schrodinger, Inc.) and UCSF Chimera 1.11 [46] were employed to analyze and identify the hydrogen-bonding interactions of the docked complexes. The observed results suggested that the followed strategy 


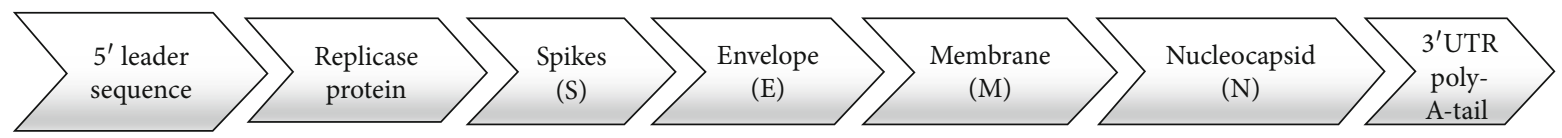

FIGURE 1: The organization of Coronavirus genome, which contains a $5^{\prime}$ end, a leader sequence, replicase protein (important for replication of whole genome), spikes, envelope, membrane, nucleocapsid, and a $3^{\prime}$ UTR poly-A-tail end.

Table 1: Predicted CTL epitopes from the SARS-CoV-2 and predicted amino acid residues (in bold) having antigenic sites.

\begin{tabular}{|c|c|c|c|c|c|c|}
\hline $\begin{array}{l}\text { Residue } \\
\text { number }\end{array}$ & $\begin{array}{l}\text { Peptide } \\
\text { sequence }\end{array}$ & $\begin{array}{l}\text { Predicted MHC binding } \\
\text { affinity }\end{array}$ & $\begin{array}{c}\text { Rescale binding } \\
\text { affinity }\end{array}$ & $\begin{array}{l}\text { C-terminal cleavage } \\
\text { affinity }\end{array}$ & $\begin{array}{c}\text { TAP transport } \\
\text { efficiency }\end{array}$ & $\begin{array}{l}\text { Prediction } \\
\text { score }\end{array}$ \\
\hline 174 & GTDLEGNFY & 0.793 & 3.3669 & 0.6229 & 2.702 & 3.5954 \\
\hline 201 & TVNVLAWLY & 0.6255 & 2.6559 & 0.8852 & 2.957 & 2.9365 \\
\hline 146 & GSVGFNIDY & 0.3112 & 1.3211 & 0.9565 & 2.857 & 1.6075 \\
\hline 110 & QTFSVLACY & 0.2625 & 1.1146 & 0.9725 & 2.998 & 1.4104 \\
\hline 153 & DYDCVSFCY & 0.2097 & 0.8905 & 0.9722 & 2.706 & 1.1717 \\
\hline 93 & TANPKTPKY & 0.1676 & 0.7118 & 0.9755 & 2.723 & 0.9942 \\
\hline 46 & SEDMLNPNY & 0.1528 & 0.6489 & 0.8406 & 2.676 & 0.9088 \\
\hline 286 & LLEDEFTPF & 0.1132 & 0.4807 & 0.9503 & 2.568 & 0.7517 \\
\hline
\end{tabular}

TABLE 2: Top-ranked selected discontinuous epitopes, interacting residues, and scores.

\begin{tabular}{|c|c|c|c|}
\hline \multicolumn{4}{|c|}{ Predicted discontinuous epitopes } \\
\hline $\begin{array}{l}\text { Sr. } \\
\text { No. }\end{array}$ & Residues & $\begin{array}{l}\text { Number of } \\
\text { residues }\end{array}$ & Score \\
\hline 1 & $\begin{array}{c}\text { A:R40, A:C44, A:T45, A:S46, A:E47, A:D48, A:M49, A:L50, A:N51, A:P52, A:N53, A:Y54, A:D56, A:L57, } \\
\text { A:I59, A:R60, A:V186, A:D187, A:R188, A:Q189, A:T190 }\end{array}$ & 21 & 0.784 \\
\hline 2 & A:Q244, A:D245, A:V247, A:D248 & 4 & 0.725 \\
\hline 3 & $\begin{array}{l}\text { A:S1, A:G2, A:F3, A:T198, A:V212, A:I213, A:N214, A:G215, A:D216, A:R217, A:W218, A:F219, A:L220, } \\
\text { A:N221, A:R222, A:F223, A:T224, A:T225, A:T226, A:L227, A:N228, A:D229, A:F230, A:N231, A:L232, } \\
\text { A:V233, A:A234, A:M235, A:K236, A:Y237, A:N238, A:Y239, A:E240, A:P241, A:L242, A:T243, A:G251, } \\
\text { A:P252, A:S254, A:A255, A:Q256, A:T257, A:G258, A:I259, A:A260, A:L262, A:D263, A:A266, A:S267, } \\
\text { A:K269, A:E270, A:L271, A:L272, A:Q273, A:N274, A:G275, A:M276, A:N277, A:G278, A:R279, A:T280, } \\
\text { A:I281, A:L282, A:G283, A:S284, A:A285, A:L286, A:S301, A:G302, A:V303, A:T304, A:F305, A:Q306 }\end{array}$ & 73 & 0.712 \\
\hline 4 & $\begin{array}{r}\text { A:G11, A:K12, A:G15, A:C16, A:T21, A:C22, A:G23, A:T24, A:T26, A:D33, A:D34, A:E55, A:L58, A:K61, } \\
\text { A:S62, A:N63, A:H64, A:N65, A:L67, A:Q69, A:A70, A:G71, A:N72, A:V73, A:Q74, A:L75, A:R76, A:V77, } \\
\text { A:I78, A:G79, A:H80, A:S81, A:K90, A:V91, A:D92, A:T93, A:A94, A:N95, A:P96, A:K97, A:T98, A:P99, } \\
\text { A:K100, A:N119, A:G120, A:D155, A:C156 }\end{array}$ & 47 & 0.707 \\
\hline 5 & A:G183, A:P184, A:F185, A:A191, A:Q192, A:A193, A:A194 & 7 & 0.552 \\
\hline 6 & A:L167, A:P168, A:T169, A:V171 & 4 & 0.521 \\
\hline
\end{tabular}

has the capability to identify the effective epitope-based vaccines against coronavirus SARS-CoV-2 [42, 57, 58].

2.7. Molecular Docking Analyses. The FDA-approved library was selected for virtual screening and molecular docking analyses. The selected library has 1615 FDA-approved compounds, and all the compounds were minimized through UCSF Chimera and Chemdraw to obtain the stable configurations; all these drugs were previously derived from the ZINC database. The selected library was docked against nonstructural corona virus protein (PDB: 6LU7) involved in the replication of SARS-CoV-2 genome. The molecular docking analyses were carried out through Molecular Operating Environment (MOE) [59], AutoDock tools, and AutoDock Vina [60]. Molecular docking analyses were performed having parameters as rescoring function 1, rescoring function 2, London $\mathrm{dG}=10$, placement: triangle matcher, retain: 2 , and refinement: force field $=10$ for $\mathrm{MOE}$. The best hits were selected based on S-score and root-mean-square deviation (RMSD) values.

The admetSAR server [61], Molinspiration [62], and Osiris explorer [63] were used to calculate the chemical and physical properties of drug-like hits. The interacting residues were analyzed and visualized through the UCSF Chimera and Ligplot tool [64].

2.8. MEV Construction and Molecular Docking Analyses. Replicase protein, NSP1, spikes, membrane, nucleocapsid and envelope proteins were retrieved by utilizing UniProt KB $[65,66]$. HTL and CTL epitopes from the selected 


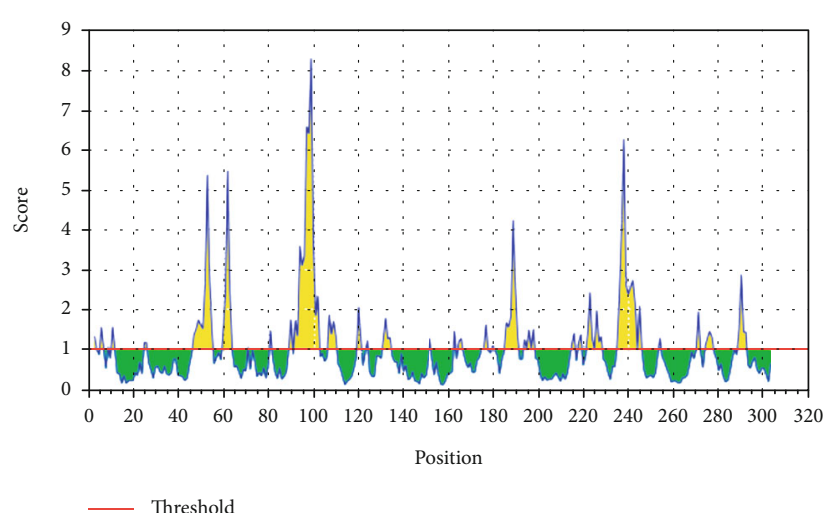

(a)

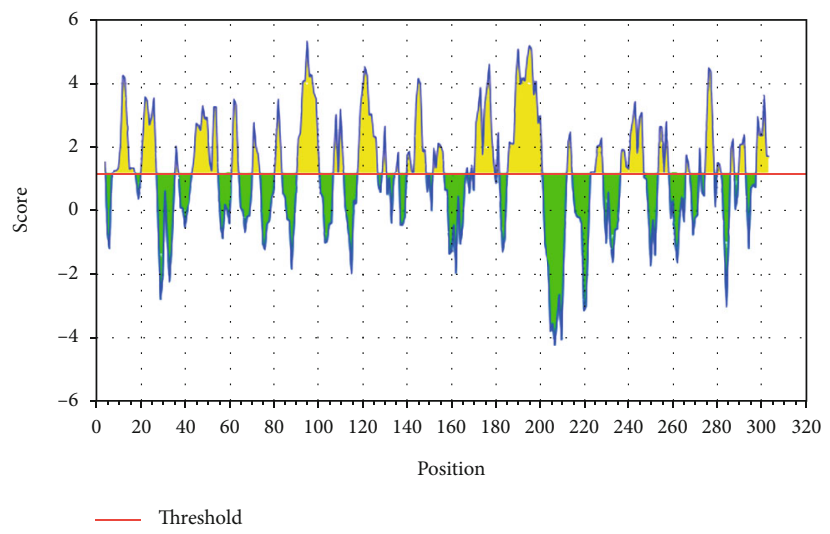

(c)

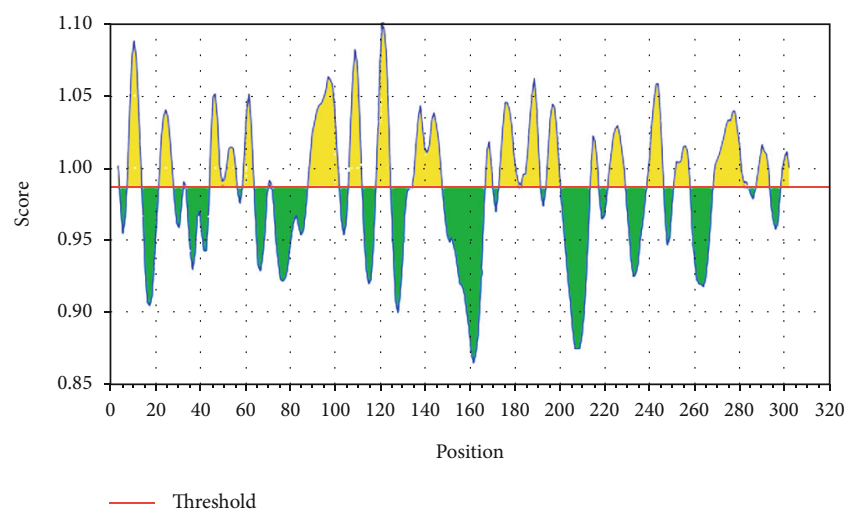

(b)

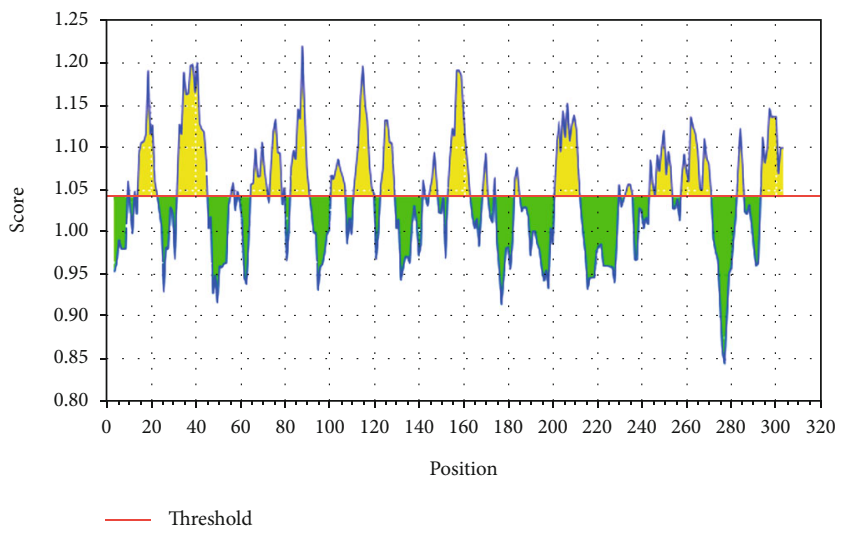

(d)

FIgure 2: Surface accessibility, surface flexibility, Parker's hydrophilicity, and antigenicity predictions evaluated by the IEDB server for nonstructural protein (PDB: 6LU7) representing the surface probability scores of the residues (a-d), respectively. Sequence positions are represented along the $x$-axis while probability scores are represented along the $y$-axis.

proteins were predicted by using the NETCTL server and ABCpred server [67]. Their physiochemical properties, antigenicity, toxicity, and immunogenicity were predicted by using the ProtParam, Vaxijen, Toxinpred, and IEDB servers, respectively $[68,69]$. An adjuvant-based MEV construct was designed manually by using the selected 28 epitopes, and $3 \mathrm{D}$ structures were predicted by using RaptorX [70]. Structure validation was carried out by the SAVES server, and the refined structures were docked with TLR3 and TLR8 by using the HADDOCK server [71, 72].

\section{Results}

The viral pneumonia with unknown etiology had an outbreak recently in Wuhan, China [13]. Severe acute respiratory syndrome (SARS), Middle East respiratory syndrome (MERS), influenza virus, and adenovirus were not involved in the outbreak of viral pneumonia [73]. The virological.org sequenced the viral RNA genome, and World Health Organization (WHO) [74] reported the designation on 10th of January 2020. Based on genetic properties, the Coronavirinae family consists four genera including alpha-coronavirus, genus beta-coronavirus, genus gamma-coronavirus, and genus delta-coronavirus (Supplementary 1) [75].
CoVs have considered as minimal responsible pathogens causing "colds" in humans. Two extremely pathogenic CoVs named as SARS-CoV and MERS-CoV were emerged from the livestock reservoirs and caused deadly outbreaks in the 21st century. A new strain of $\mathrm{CoV}$ was identified named as SARS-CoV-2 in Wuhan city on December 31st, 2019. Due to the rapid changing situation, the final dimension and impact of this outbreak are currently uncertain [76]. The novel virus infects the host cells rapidly, proven through recombination of various genome practices. For this infection, no reliable mediation is currently available. The preventative measures are urgently needed due to the significant global disease burden resultant of SARS-CoV-2 [77]. A variety of tools and servers have resulted through recent advancement in immunological bioinformatics, which lessens the time and cost of traditional vaccine advancement. The development of an effective multiple-epitope vaccine remains difficult, due to problems in the selection of suitable antigen candidates and immune-dominant epitopes. Thus, it is important to predict the appropriate antigen epitopes of a targeted protein by immune-informatics approaches for designing a multiple-epitope vaccine [48]. The main target is to use immune-informatics approaches and the prediction of peptide vaccine through recognizing CTL epitopes. The discovery of novel vaccines is possible through 
TABLE 3: Summary of designed peptides against SARS-CoV-2 peptides-MHC class I HLA-B interactions.

\begin{tabular}{|c|c|c|c|c|c|c|}
\hline Peptide & $\begin{array}{c}\text { Global energy } \\
(\mathrm{kcal} / \mathrm{Mol})\end{array}$ & $\begin{array}{l}\text { Attractive VdW energy } \\
(\mathrm{kcal} / \mathrm{Mol})\end{array}$ & $\begin{array}{l}\text { H-Bond energy } \\
(\mathrm{kcal} / \mathrm{Mol})\end{array}$ & $\begin{array}{l}\text { Peptidase-MHC } \\
\text { pair }\end{array}$ & $\begin{array}{c}\text { Bond } \\
\text { distance }(\AA)\end{array}$ & $\begin{array}{c}\text { Conserved } \\
\text { residues }\end{array}$ \\
\hline GTDLEGNFY & -43.24 & -28.87 & 0.22 & $\begin{array}{c}\text { PHE8 O-ARG156 } \\
\text { A } \\
\text { THR2 O-ILE66 } \\
\text { CD1 } \\
\text { THR2 N-ARG62 } \\
\text { NH2 } \\
\text { ASN7 OD1- } \\
\text { TYR99 OH } \\
\text { TYR9 CZ-TRP147 } \\
\text { CE2 } \\
\text { SER4 CB-ILE66 } \\
\text { CD1 }\end{array}$ & $\begin{array}{l}2.020 \\
2.474 \\
2.575 \\
1.319 \\
2.194 \\
2.315\end{array}$ & $\begin{array}{c}\text { TYR9 } \\
\text { ARG62 } \\
\text { ILE66 } \\
\text { THR73 } \\
\text { TYR99 } \\
\text { GLU152 }\end{array}$ \\
\hline TVNVLAWLY & -50.38 & -32.3 & -3.03 & $\begin{array}{c}\text { LEU8 C-TYR99 } \\
\text { OH } \\
\text { LEU8 O-TYR99 } \\
\text { OH } \\
\text { ALA6 O-ILE66 } \\
\text { HG22 } \\
\text { TRP7 CG-GLN70 } \\
\text { CD } \\
\text { TYR9 O1-IL66 } \\
\text { CG2 } \\
\text { SER4 CB-ILE66 } \\
\text { CD1 }\end{array}$ & $\begin{array}{l}2.573 \\
1.960 \\
1.768 \\
2.688 \\
2.497 \\
1.596\end{array}$ & $\begin{array}{c}\text { TYR9 } \\
\text { ARG62 } \\
\text { ILE66 } \\
\text { THR73 } \\
\text { TYR99 } \\
\text { GLU152 }\end{array}$ \\
\hline GSVGFNIDY & -42.49 & -27.33 & -1.15 & $\begin{array}{c}\text { PHE5 O-THR73 } \\
\text { OG1 } \\
\text { PHE5 O-THR73 } \\
\text { CB } \\
\text { SER2 O-ILE66 } \\
\text { CG2 } \\
\text { ASP8 OD2- } \\
\text { TYR99 CD1 } \\
\text { ASN6 N-THR73 } \\
\text { CG2 } \\
\text { GLY4 CA-GLN70 } \\
\text { OE1 }\end{array}$ & $\begin{array}{l}0.425 \\
1.321 \\
2.103 \\
2.144 \\
2.559 \\
2.698\end{array}$ & $\begin{array}{c}\text { TYR9 } \\
\text { ARG62 } \\
\text { ILE66 } \\
\text { THR73 } \\
\text { TYR99 } \\
\text { GLU152 }\end{array}$ \\
\hline QTFSVLACY & -40.01 & -23.86 & -1.887 & $\begin{array}{c}\text { TYR9 C-TYR116 } \\
\text { OH } \\
\text { LEU6 O-ARG156 } \\
\text { HD3 } \\
\text { SER4 CB-ILE66 } \\
\text { CD1 } \\
\text { CYS8 CB-TYR99 } \\
\text { OH } \\
\text { GLN1 OE1-ILE66 } \\
\text { N } \\
\text { CYS8 O-TYR99 } \\
\text { CD1 }\end{array}$ & $\begin{array}{l}1.475 \\
1.634 \\
2.744 \\
2.682 \\
2.011 \\
2.493\end{array}$ & $\begin{array}{c}\text { TYR9 } \\
\text { ARG62 } \\
\text { ILE66 } \\
\text { THR73 } \\
\text { TYR99 } \\
\text { GLU152 }\end{array}$ \\
\hline DYDCVSFCY & -40.48 & -26.48 & -1.2 & $\begin{array}{c}\text { CYS8 CB-GLN70 } \\
\text { OE1 } \\
\text { PHE7 CZ-ARG62 } \\
\text { NH1 } \\
\text { CYS8 SG-GLN70 } \\
\text { OE1 } \\
\text { ASP1 CG- } \\
\text { GLU154 O } \\
\text { GLN1 OE1-ILE66 } \\
\text { N }\end{array}$ & $\begin{array}{l}0.952 \\
1.159 \\
1.542 \\
2.571 \\
2.253 \\
1.693\end{array}$ & $\begin{array}{c}\text { TYR9 } \\
\text { ARG62 } \\
\text { ILE66 } \\
\text { THR73 } \\
\text { TYR99 } \\
\text { GLU152 }\end{array}$ \\
\hline
\end{tabular}


TABLe 3: Continued.

\begin{tabular}{|c|c|c|c|c|c|c|}
\hline Peptide & $\begin{array}{c}\text { Global energy } \\
(\mathrm{kcal} / \mathrm{Mol})\end{array}$ & $\begin{array}{l}\text { Attractive VdW energy } \\
(\mathrm{kcal} / \mathrm{Mol})\end{array}$ & $\begin{array}{l}\text { H-Bond energy } \\
(\mathrm{kcal} / \mathrm{Mol})\end{array}$ & $\begin{array}{l}\text { Peptidase-MHC } \\
\text { pair }\end{array}$ & $\begin{array}{c}\text { Bond } \\
\text { distance }(\AA)\end{array}$ & $\begin{array}{c}\text { Conserved } \\
\text { residues }\end{array}$ \\
\hline TANPKTPKY & -32.96 & -23.45 & -1.65 & $\begin{array}{c}\text { CYS8 O-TYR99 } \\
\text { CD1 } \\
\text { TYR9 C-THR73 } \\
\text { OG1 } \\
\text { LYS8 O-THR73 } \\
\text { HG21 } \\
\text { PRO7 CD- } \\
\text { TRP147 CZ2 } \\
\text { LYS5 CE-TYR99 } \\
\text { OH } \\
\text { THR6 CA- } \\
\text { TYR116 HH }\end{array}$ & $\begin{array}{l}1.336 \\
0.712 \\
2.509 \\
2.317 \\
2.027 \\
2.693\end{array}$ & $\begin{array}{c}\text { TYR9 } \\
\text { ARG62 } \\
\text { ILE66 } \\
\text { THR73 } \\
\text { TYR99 } \\
\text { GLU152 }\end{array}$ \\
\hline SEDMLNPNY & -29.63 & -26.6 & -0.72 & $\begin{array}{c}\text { SER1 CB-THR73 } \\
\text { OG1 } \\
\text { LEU5 CD2- } \\
\text { GLN70 OE1 } \\
\text { MET4 CE-ILE66 } \\
\text { CA } \\
\text { TYR9 O1-TYR159 } \\
\text { HB2 }\end{array}$ & $\begin{array}{l}0.732 \\
1.252 \\
2.377 \\
1.283 \\
1.986 \\
2.563\end{array}$ & $\begin{array}{c}\text { TYR9 } \\
\text { ARG62 } \\
\text { ILE66 } \\
\text { THR73 } \\
\text { TYR99 } \\
\text { GLU152 }\end{array}$ \\
\hline LLEDEFTPF & -35.13 & -32.62 & -3.99 & $\begin{array}{c}\text { PRO8 CB-THR73 } \\
\text { OG1 } \\
\text { LEU1 N-ARG156 } \\
\text { CD } \\
\text { GLU5 O-ILE66 } \\
\text { HG22 } \\
\text { SER1 CB-THR73 } \\
\text { OG1 } \\
\text { LEU5 CD2- } \\
\text { GLN70 OE1 } \\
\text { MET4 CE-ILE66 } \\
\text { CA }\end{array}$ & $\begin{array}{l}1.679 \\
1.813 \\
1.750 \\
1.569 \\
2.576 \\
2.201\end{array}$ & $\begin{array}{c}\text { TYR9 } \\
\text { ARG62 } \\
\text { ILE66 } \\
\text { THR73 } \\
\text { TYR99 } \\
\text { GLU152 }\end{array}$ \\
\hline
\end{tabular}

pathogenomics analyses on a genome wide scale, though these conventional experimental methods have multiple limitations [78]. To analyze the complete spectrum of the potential antigen, immune-informatics approaches help, and furthermore, complications regarding in vitro expression of antigen and pathogen culturing can also be evaded. By means of computational methods, the immune research groups have reported various vaccine candidates, having promising preclinical outputs [79]. In current efforts, CTL epitopes have been identified to design the peptide vaccine against HLA-B protein [80]. The development of epitope-based vaccines targets the structural proteins of SARS-CoV-2, and CTL epitopes of the target proteins were predicted to support the host's immune response. One nonstructural protein (PDB: 6LU7) stands with the reason to use this nonstructural protein due to involvement in the replication of the virus [8187]. The antigenicity and allergenicity of CTL epitopes were observed through Vaxijen and Allergen F.P 1.0 [88]. The population coverage estimation of predicted epitopes was calculated, and 0.5639 coverage with average hits of 4.0 for $\mathrm{MHC}$ class I and 0.2462 coverage with average hits of 0.91 for MHC class II (Table 1) were observed in China. The peptides were designed against eight epitopes by utilizing PEPFOLD3. The molecular docking analyses of the selected eight peptides were performed through PatchDock and further refined through FireDock [53-55] to identify the effective binding sites.

3.1. Surface Accessibility Analysis for SARS-CoV-2. A peptide with surface accessibility probability of $>1.0$ reflects more probable chances for a peptide to be found on the surface [43]. Numerous peptides were predicted, and the topranked predicted peptides of SARS-CoV-2 on the basis of surface probability ( $y$-axis) and sequence position ( $x$-axis) were selected for further analyses (Figure 2(a)). The maximum surface probability score of 8.254 was observed that ranges from 97 to 102 amino acids with the hexapeptide sequence of KTPKYK, while the lowest score was 0.285 from 246 to 251 residues with the hexapeptide sequence of HVDILG (Supplementary 2).

3.2. Surface Flexibility for Protein SARS-CoV-2. The Karplus and Schulz flexibility method was utilized to calculate and analyze the atomic vibrational motions in the protein structure designated through B-factor and temperature. The stability and organization of the structure depend upon the Bfactor values. The quality of the predicted models depends upon the B-factor values as a lower B-factor value is 


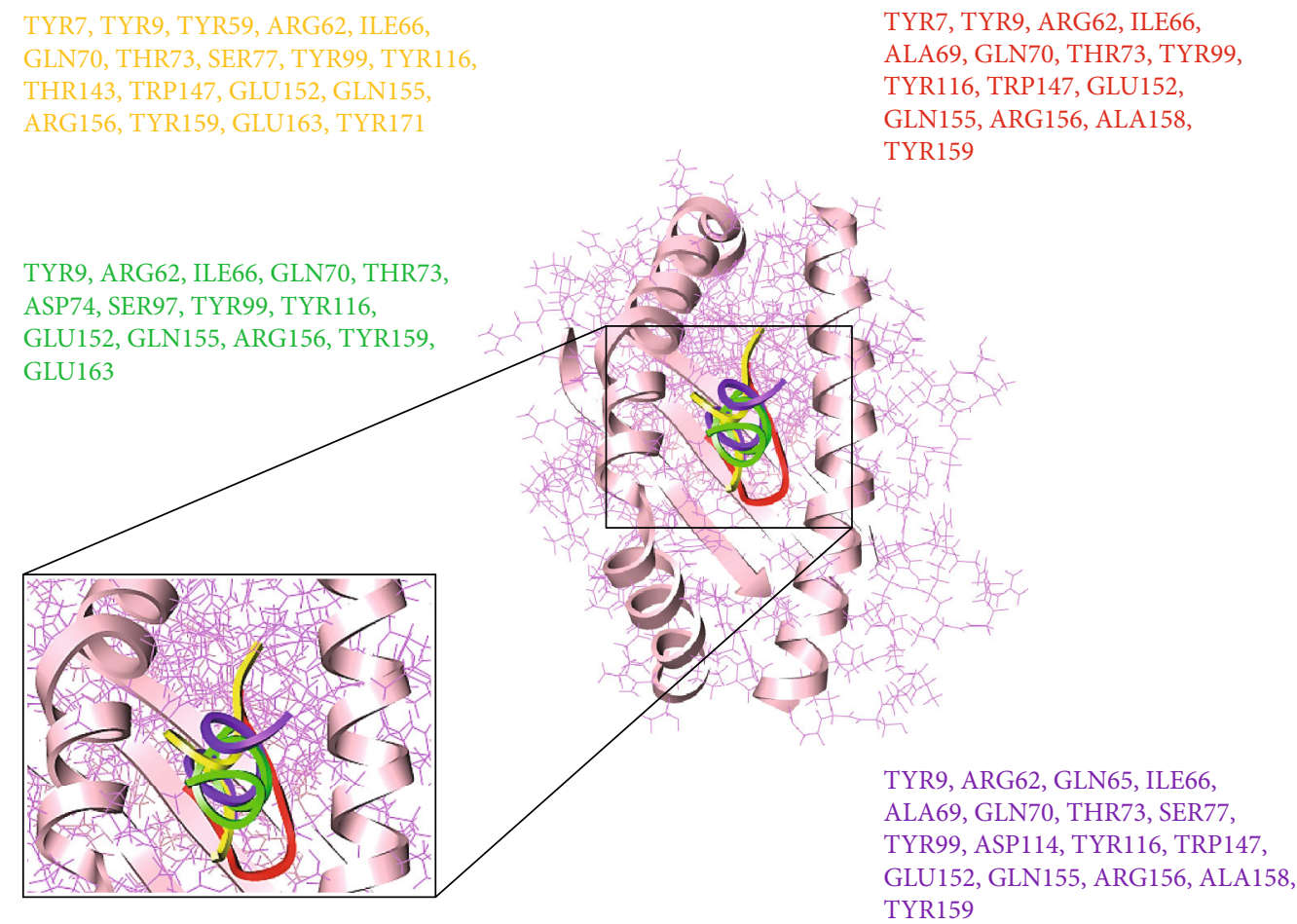

Figure 3: Peptide-MHC class I HLA-B binding interacting residues of four top-ranked peptides represented in different colors.

considered an effective model while higher B-factor values lead to the less-organized and poorly ordered structures [44]. The surface flexibility outputs for SARS-CoV-2 were critically analyzed (Figure 2(b)), and it was observed that the minimum and maximum flexibility scores were 0.983 and 1.082 with the heptapeptide sequences of 129 AMRPNFT 135 and 106 IQPGQTF 112, respectively (Supplementary 2).

3.3. Parker Hydrophilicity Prediction for SARS-CoV-2. The hydrophilicity scale process of Parker was carried out to observe the peptides hydrophilicity based on the peptide retention times through HPLC on reversed phase column. Immunological analyses have revealed the association of antigenic sites with the hydrophilic regions [43]. Parker's hydrophilicity of SARS-CoV-2-predicted peptides in graphical form was analyzed (Figure 2(c)), where hydrophilicity is plotted along the $y$-axis and residues position is plotted along the $x$-axis.

It was observed that the Parker hydrophilicity prediction has a maximum hydrophilicity score of 5.329 which ranges from 92 to 98 with the sequence of heptapeptide 92 DTANPKT 98 while the minimum hydrophilicity score was -4.257 which ranges from 204 to 210 with the peptide sequence 204 VLAWLYA 210 (Supplementary 2).

3.4. Kolaskar and Tongaonkar Antigenicity Prediction for SARS-CoV-2. The antigenicity of SARS-CoV-2 was calculated through the Kolaskar and Tongaonkar method (Figure 2(d)), the maximum antigenicity values for two top-ranked peptides were observed as 1.197 for VVYCPRH and VYCPRHV at positions 35 to 41 and 36 to 42 , respec- tively, and the minimum predicted antigenicity was 0.844 for NGMNGRT from position 274 to 280 (Supplementary 2).

3.5. Structure-Based Epitope Prediction for SARS-CoV-2. The correlation among the protein structure antigenicity, epitope prediction, accessibility, and flexibility within 3D structure was determined through ElliPro [89]. The significant properties including protein-antibody interactions were analyzed to differentiate the predicted epitopes. The five top-ranked conformational epitopes for SARS-CoV-2 having $\geq 0.6$ score were observed and selected for further analyses. The $\mathrm{pI}$ (isoelectric point value) [89] score was observed to analyze the percentage of the atoms which extends over the molecular bulk and also liable for the antibody binding. The pI value 5.95 was observed for 6LU7. The six top-ranked conformational predicted epitopes along with residues name, length, and locations were critically analyzed (Table 2 ), and the score was observed between 0.51 and 0.78 .

3.6. Molecular Docking Analyses of SARS-CoV-2 with HLA-B. The comparative molecular docking analyses were executed for 8 top-ranked selected CTL epitopes of SARS-CoV-2 out of 87 designed peptides with MHC class I HLB. The strong binding affinities have been observed for all the selected CTL epitopes having Van der Waals (VdW) energy values ranging from -23.45 to $-32.62 \mathrm{kcal} / \mathrm{mol}$, and the observed global energy was -29.63 to $-50.38 \mathrm{kcal} / \mathrm{mol}$ (Table 3 ). The molecular docking analyses of the 8 selected CTL predicted epitopes (GTDLEGNFY, TVNVLAWLY, GSVGFNIDY, QTFSVLACY, DYDCVSFCY, TANPKTPKY, SEDMLNPNY, and LLEDEFTPF) were carried out, and effective binding affinities with HLA-B were observed. 
<smiles>CCC1C2CC(OC(O)N3CCC(N4CCCCC4)CC3)CCC2NC2C1CN1C(O)C3CO[C@@](O)(CC)[C@H]3CC21</smiles>

(a)

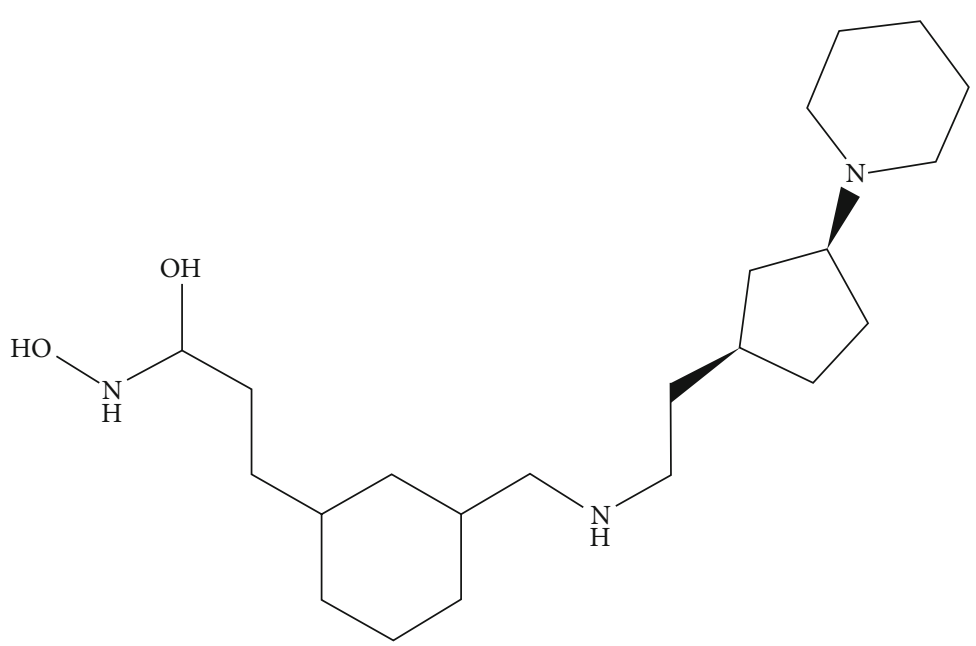

(b)

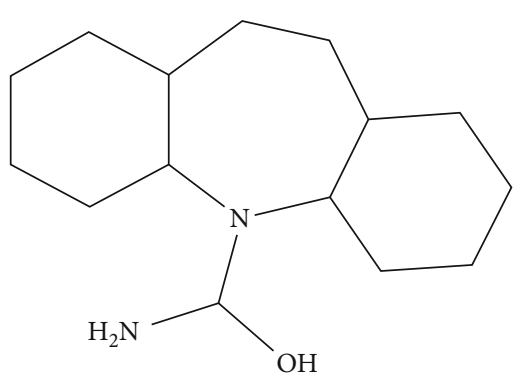

(d)

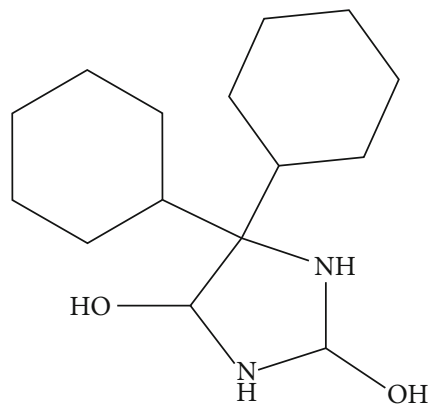

(c)

Figure 4: Four selected FDA-approved drugs (a) FDA-7, (b) FDA378, (c) FDA670, and (d) FDA592.

The top-ranked four docked complexes were visualized (Figure 3), and similar binding pocket has been observed in all the selected peptides. It was observed that Tyr9, Ile66, Gln70, Tyr99, Tyr116, and Arg156 residues were conserved in all the selected peptides.

3.7. Population Coverage Analyses. The population coverage analyses were performed with the selected MHC class I and MHC class II epitopes and also with the associated HLA alleles. It was observed that the selected MHC class I and
MHC class II epitopes have the world's population of $58.49 \%$ and $34.71 \%$, respectively. MHC class I epitopes showed highest coverage in the population of Italy $(0.9019 \%)$ and China $(0.5639 \%)$. The MHC class II epitopes also showed highest coverage in Philippines (0.7192\%) (Supplementary 3 ).

3.8. Multiple Sequence Alignment. Multiple sequence alignment (MSA) of three coronavirus genomes were performed, and conserved binding residues were detected. It was 


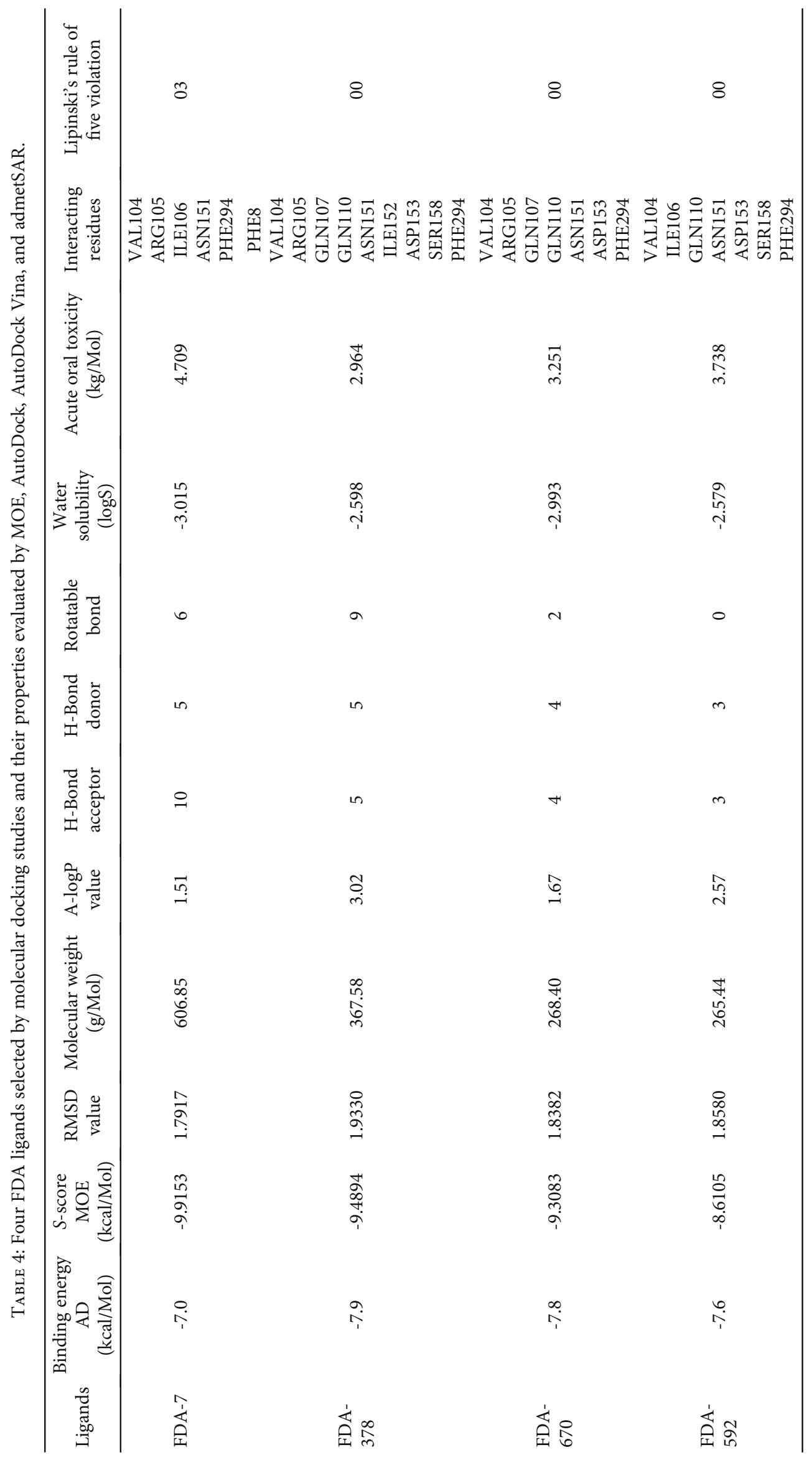




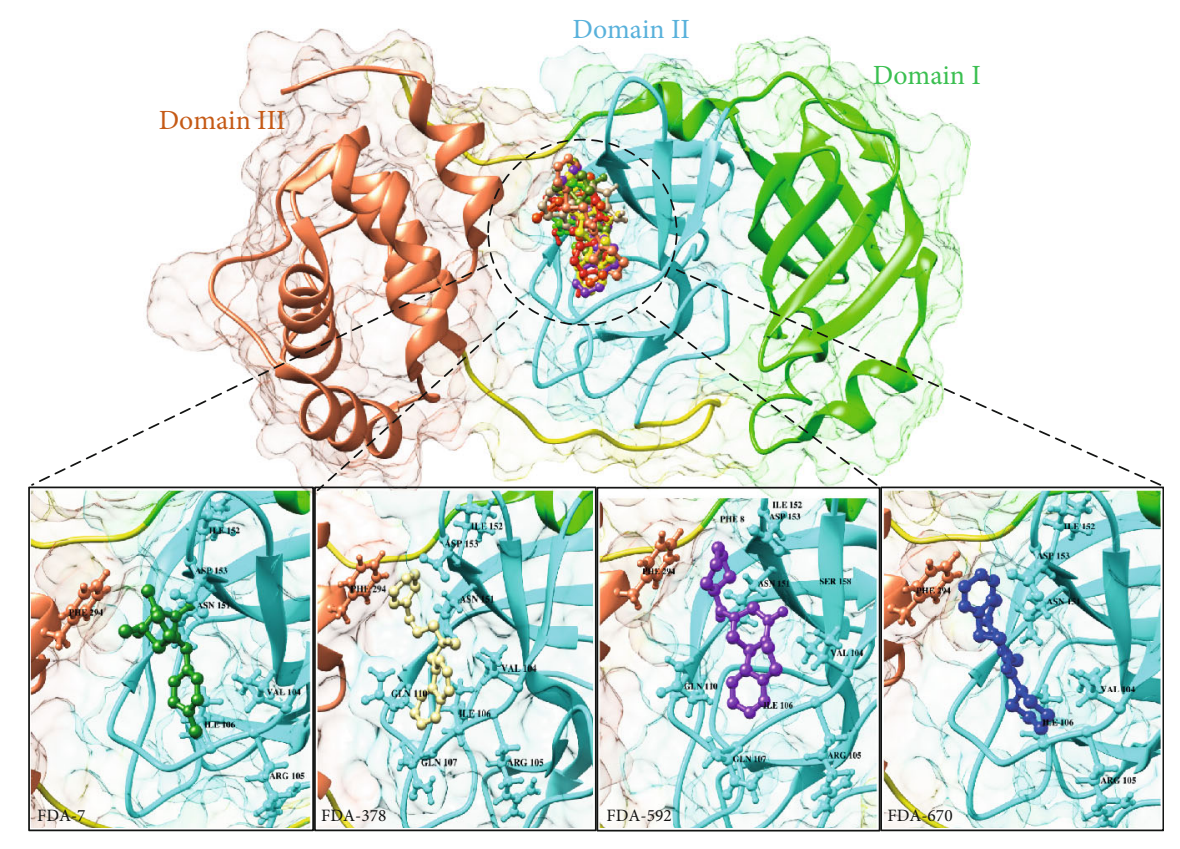

Figure 5: Nonstructural protein (PDB: 6LU7) has three domains, domain I from 8-99a.a (green), domain II from 100-183a.a (cyan), and domain III from 200-306a.a (brown). A conserved binding pocket present in domain II is observed while docked with FDA ligands. Top 4 ligands from FDA library have conserved interacting residues, FDA-7 (olive green), FDA-378 (skin), FDA-592 (purple), and FDA-670 (blue).

observed that all the selected strains of coronavirus have conserved domains, reconciling with the latest outbreak strain SARS-CoV-2. Interestingly, it was observed that the reported binding domain of previously reported strain has similar region of binding with the latest outbreak of Coronavirus 2019. The binding residues of SARS-CoV-2 showed similar binding domain with the MERS and SARS (Supplementary 4).

3.9. Comparative Molecular Docking Analyses. The in silico analyses revealed that the selected peptides have significant values against SARS-CoV-2. The comparative molecular docking analyses have been performed against the selected library of ZINC database. The molecular docking analyses showed variations in their binding energies. The FDA library (1615 compounds) [90] of ZINC database was screened through molecular docking analyses. The comparative molecular docking analyses were carried out on the selected library of 1615 compounds by using MOE, AutoDock tools, and AutoDock Vina. The blind and targeted docking was performed for the complete library (FDA library) against the selected protein. The common top-ranked compounds from blind and targeted docking were selected for further analyses. All the observed complexes of the compounds were ranked on the basis of interacting residues, highest binding affinities, drug properties, and least binding energy. The nine top-ranked docked complexes collectively from all the selected tools and docking approaches were critically visualized and analyzed. It was observed that the molecules FDA7, FDA-378, FDA-499, and FDA-1262 (Figure 4) from the selected library were common from each selected docking tool and docking approach having least binding energies (Table 4). Almost all the docked compounds from the FDA library bound on similar binding site. The four top-ranked complexes were elucidated (Figure 4), and similar binding pocket was revealed in comparison with molecular docking analyses. The selected compounds may have the potential to inhibit the replication of SARS-CoV-2. It was elucidated that all the compounds bound at the domain II of SARSCoV-2.

It was observed that Asp153, Phe294, Ile152, Asn151, Val104, Arg105, Gln107, Gln110, and Ile106 residues showed effective binding interactions with all the docked compounds of the FDA library. In an effort to understand the insights of the binding interactions between the docked compounds and amino acid residues of SARS-CoV-2, a plot of interactional analyses was generated by utilizing Ligplot and UCSF Chimera (Figure 5).

The FDA library has all the compounds approved by the FDA and utilized for different diseases. The FDA library's aim was to select the available compounds to inhibit the replication of SARS-CoV-2 in minimal time frame. Molinspiration, admetSAR online server, and Osiris explorer were utilized for absorption, distribution, metabolism, excretion, and toxicity (ADMET) analyses of the selected compounds (Table 4). The aqueous solubility prediction (defined water at $25^{\circ} \mathrm{C}$ ) of the selected library revealed that the scrutinized molecules can be soluble in water. It was observed that the compounds have the ability to follow Lipinski's rule of five and also have less values of LogP involved in effective oral bioavailability. All the selected nine compounds showed similar binding site and highest binding affinity (Supplementary 5).

3.10. Target Protein Sequence and Structure Prediction. The amino acid sequences of SARS-CoV-2 vaccine-target proteins (replicase protein, NSp1, envelope, membrane, nucleocapsid, and spike protein) were retrieved and saved in 
TABLE 5: Selected epitopes for MEV along with their antigenicity, binding affinities, and other properties.

\begin{tabular}{|c|c|c|c|c|c|c|c|c|c|}
\hline $\begin{array}{l}\text { Sr. } \\
\text { No. }\end{array}$ & Protein & Epitopes & Antigenicity & $\begin{array}{c}\text { Binding score } \\
\text { (kcal/Mol) with } \\
\text { HLA-B7 }\end{array}$ & $\begin{array}{l}\text { Predicted } \\
\text { MHC } \\
\text { binding } \\
\text { affinity }\end{array}$ & $\begin{array}{l}\text { Rescale } \\
\text { binding } \\
\text { affinity }\end{array}$ & $\begin{array}{l}\text { C-terminal } \\
\text { cleavage } \\
\text { affinity }\end{array}$ & $\begin{array}{c}\text { TAP } \\
\text { transport } \\
\text { efficiency }\end{array}$ & Position \\
\hline \multicolumn{10}{|c|}{ MHC class I } \\
\hline 1 & Nsp1 & HVGEIPVAY & 0.81 & -11.76 & 1.193 & 4.366 & 0.229 & 1.702 & $37-45$ \\
\hline 2 & Nsp1 & LSEARQHLK & 0.16 & -11.55 & 0.325 & 3.659 & 0.852 & 2.957 & $60-68$ \\
\hline 3 & Replicase & GSVGFNIDY & 1.52 & -14.25 & 1.212 & 0.311 & 0.955 & 0.857 & $12-21$ \\
\hline 4 & Replicase & LLEDEFTPF & 2.37 & -10.22 & 1.651 & 2.146 & 0.972 & 3.998 & $31-39$ \\
\hline 5 & Envelope & LVKPSFYVY & 0.63 & -10.36 & 1.297 & 3.905 & 0.942 & 2.706 & $9-17$ \\
\hline 6 & Membrane & LVGLMWLSY & 0.54 & -10.87 & 0.176 & 2.718 & 0.755 & 0.723 & $54-62$ \\
\hline 7 & Membrane & AGDSGFAAY & 0.52 & -15.00 & 0.158 & 2.649 & 0.806 & 1.676 & $93-101$ \\
\hline 8 & Nucleocapsid & LSPRWYFYY & 0.87 & -14.78 & 0.113 & 2.480 & 0.973 & 2.518 & $99-107$ \\
\hline 9 & Nucleocapsid & SSPDDQIGY & 0.65 & -13.57 & 0.693 & 0.369 & 0.621 & 2.602 & $154-162$ \\
\hline 10 & Spikes & WTAGAAAYY & 0.35 & -12.22 & 0.625 & 1.659 & 0.892 & 2.937 & $27-35$ \\
\hline 11 & Spikes & CNDPFLGVY & 1.32 & -12.63 & 0.812 & 6.211 & 0.365 & 2.857 & $59-67$ \\
\hline 12 & Spikes & ITDAVDCAL & 1.52 & -15.21 & 0.713 & 3.369 & 0.629 & 2.700 & $71-79$ \\
\hline 13 & Spikes & STQDLFLPF & 0.57 & -11.36 & 0.631 & 0.651 & 0.880 & 2.857 & $88-96$ \\
\hline 14 & Spikes & QLTPTWRVY & 2.0 & -10.28 & 0.302 & 2.611 & 0.915 & 2.352 & $112-120$ \\
\hline 15 & Spikes & VLPFNDGVY & 1.70 & -14.27 & 0.005 & 3.106 & 0.025 & 2.908 & $137-145$ \\
\hline 16 & Spikes & YQDVNCTEV & 0.08 & -14.26 & 0.117 & 2.835 & 0.932 & 2.716 & $199-207$ \\
\hline \multicolumn{10}{|c|}{ MHC class II } \\
\hline 17 & Nsp1 & DLGDELGTDPYEDFQ & 0.12 & -11.32 & 0.693 & 2.366 & 0.663 & 2.976 & $69-83$ \\
\hline 18 & Replicase & TLNGLWLDDVVYCPR & 0.77 & -12.88 & 0.723 & 0.659 & 0.872 & 2.126 & $101-115$ \\
\hline 19 & Envelope & VLLFLAFVVFLLVTL & 2.52 & -11.01 & 1.556 & 3.311 & 0.365 & 2.357 & $99-113$ \\
\hline 20 & Membrane & LACFVLAAVYRINWI & 1.37 & -13.73 & 1.327 & 2.146 & 0.985 & 2.256 & $127-141$ \\
\hline 21 & Membrane & CLLQFAYANRNRFLY & 0.33 & -14.58 & 0.786 & 2.805 & 0.900 & 2.799 & $196-210$ \\
\hline 22 & Membrane & AVYRINWITGGIAIA & 0.55 & -10.27 & 0.456 & 1.718 & 0.002 & 2.159 & $222-236$ \\
\hline 23 & Nucleocapsid & QIGYYRRATRRIRGG & 0.83 & -10.66 & 0.551 & 4.648 & 0.116 & 2.015 & $13-27$ \\
\hline 24 & Nucleocapsid & GTWLTYTGAIKLDDK & 1.54 & -13.22 & 1.007 & 3.487 & 0.963 & 2.367 & $47-61$ \\
\hline 25 & Nucleocapsid & ATKAYNVTQAFGRRG & 1.12 & -13.37 & 1.697 & 0.369 & 0.129 & 2.449 & $68-82$ \\
\hline 26 & Nucleocapsid & GDAALALLLLDRLNQ & 2.54 & -15.24 & 0.273 & 0.559 & 0.652 & 2.441 & 171-185 \\
\hline 27 & Spikes & QSLLIVNNATNVVIK & 1.02 & -10.25 & 0.123 & 2.311 & 0.756 & 2.221 & $9-23$ \\
\hline 28 & Spikes & INITRFQTLLALHRS & 2.38 & -12.16 & 0.357 & 3.116 & 0.925 & 2.118 & $166-180$ \\
\hline
\end{tabular}

FASTA format. The VaxiJen server was used to analyze the antigenicity of the selected proteins. Spike protein was observed as the most antigenic protein, followed by E, M, $\mathrm{NSp} 1, \mathrm{~N}$, and replicase proteins with antigenic values of $0.7185,0.6502,0.6441,0.6131,0.6025$, and 0.5102 , respectively. The $3 \mathrm{D}$ models of the selected proteins were predicted in order to select the suitable quality models, and the predicted structures were further refined by galaxy refine server followed by the Ramachandran plot validations. Therefore, good-quality models were selected for further analyses. There was no suitable structure predicted for spike protein because of the small number of residues.

3.11. HLA-B7 Allele and Epitope Interaction Analyses. To construct a subunit vaccine, the selected epitopes should be $100 \%$ conserved, overlapping, and antigenic [91, 92]. Therefore, a total of 50 conserved/antigenic epitopes from the selected proteins overlapping in all 3 categories (B-cell, T- cell, and IFN- $\Gamma$ ) were selected for further validation of their interactions with a common human allele. The $3 \mathrm{D}$ structures of the selected epitopes were predicted by using PEP-FOLD. The binding patterns of the selected epitopes with a common conserved allele HLA-B7 were analyzed through molecular docking, and it was found that only 28 epitopes bound deep inside in the HLA-B7 binding pocket. Each bound epitope to HLA-B7 depicts stronger than $-10.00 \mathrm{kcal} / \mathrm{mol}$ docking affinity. All the 28 selected epitopes showed their binding efficiency as well as their suitability to be used in multiplepitope-based vaccine construct (Table 5).

3.12. Construction of Multiepitope-Based Vaccine. All 28 selected epitopes (replicase 3, NSp1 3, envelope 2, membrane 5 , nucleocapsid 6, and spikes 9) were analyzed for interinteractions and further used to develop an MEV construct. An adjuvant (45 amino acid long $B$ defensin) was linked with the help of EAAAK linker at the start (to the N-terminal of 


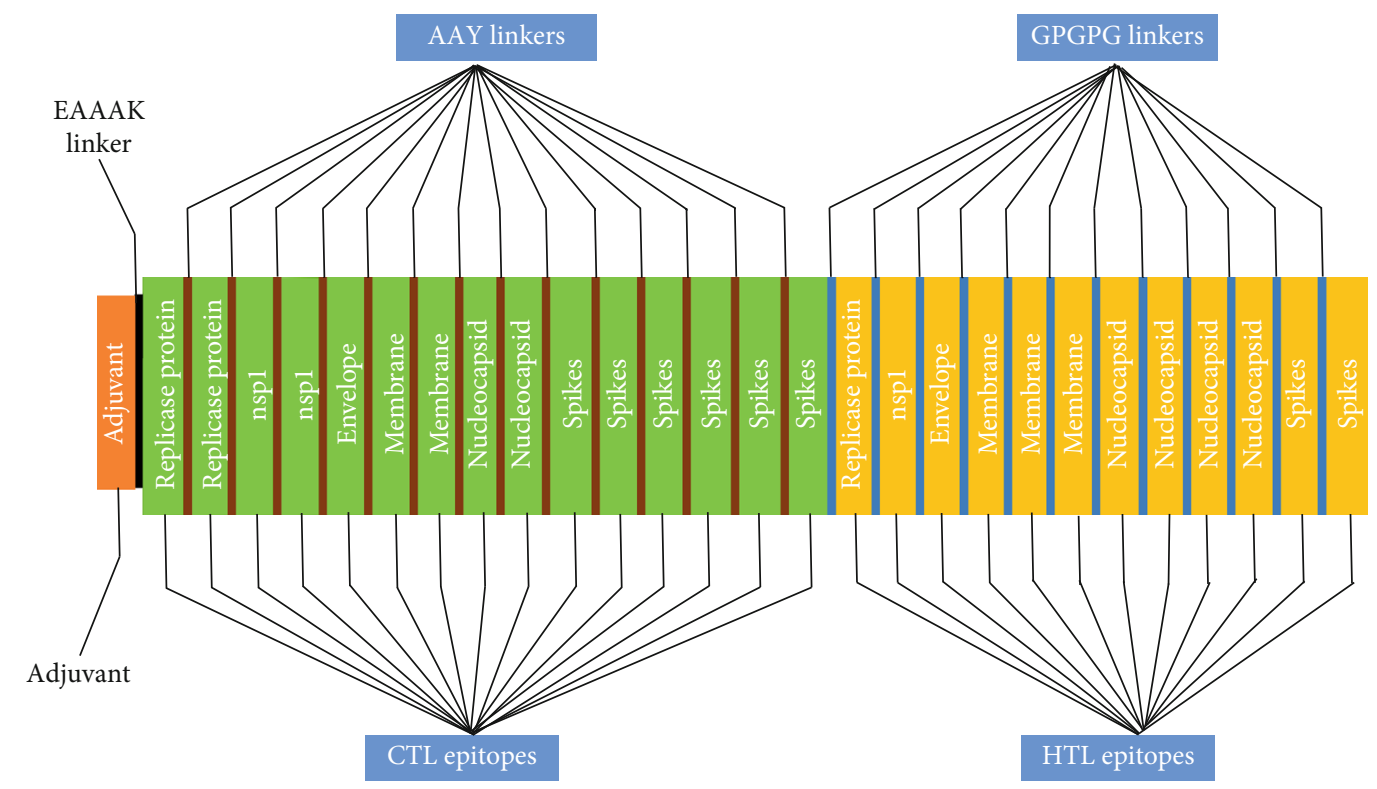

Figure 6: A multiepitope vaccine construct led by an adjuvant and all epitopes joined with linkers.

the MEV). The EAAAK linker reduces the interaction with other protein regions with efficient separation and increases the stability. The immunogenicity of the vaccine may increase with an adjuvant. Epitopes were merged together based on their interactional compatibility in sequential manner with AAY and GPGPG linkers, respectively. AAY and GPGPG prevent the generation of junctional epitopes, which is a major concern in the design of multiepitope vaccines. Contrarily, multiepitope vaccines facilitate the immunization and presentation of the epitopes. The final vaccine construct comprises of 479 amino acids (Figure 6).

3.13. Evaluation of Multiepitope Vaccine. BlastP was performed for the proteome of Homo sapiens, and it was observed that MEV is nonhomologous. Proteins having less than $37 \%$ identity was generally considered nonhomologous $[93,94]$. However, MEV showed no similarity (higher or equal to $37 \%$ ) with the proteins of human. The allergenicity, antigenicity, and toxicity of the vaccine construct were evaluated. It was observed that MEV is highly antigenic (0.6741 at $0.5 \%$ threshold), nonallergenic, and nontoxic. Furthermore, the physiochemical properties of the SARS-CoV-2 MEV construct were determined by using ProtParam. It contains 479 amino acids with $55426.35 \mathrm{KDa}$ of molecular weight, indicating good antigenic nature. The isoelectric point (pI) of MEV was 9.12 showing the negative behavior. The negatively charged MEV showed the value of pI less than 7. MEV was categorized as stable as the instability index was 33.41 . The aliphatic index was 82.75 showing the proportional volume of the aliphatic side chains. The protein sequence has a GRAVY value of 0.105 , indicating the hydrophobic nature of the MEV. The half-life of the protein was calculated as $>20$ hours for yeast, 30 hours for mammalian-reticulocytes, and $>10$ hours for E. coli.

3.14. Structural Analyses of Multiepitope-Based Vaccine. The secondary structure of MEV was predicted, and from 479 amino acids, $\alpha$-helixes were comprised of 156 amino acids representing $35.20 \%, 99$ amino acids in $\beta$-strands representing $21.59 \%$, and 215 amino acids forms the coils (42.58\%) of the MEV construct. To determine the tertiary structure of the vaccine, RaptorX was used and the structure was refined by Galaxy (Figure 7). The selected structure showed that $96.3 \%$ amino acids were in allowed region, $3.7 \%$ of residues in permitted region, and $0.0 \%$ in outer region according to the Ramachandran plot analyses. Further analyses revealed that qRMSD was 0.428 , poor rotamers were $0 \%$, MolProbity was 1.889 , clash score was 13.6 , and $Z$ score was -2.25 . In addition, the refined structure showed 0 errors with PROCHECK validation. The refined structure showed $85.7143 \%$ of the overall quality factor through ERRAT. The results showed the reliability of the selected structure. The Ramachandran plot analyses of the predicted MEV structure showed that $96.3 \%$ of residues were present in favorable region.

\subsection{Molecular Docking Analyses of Multiepitope-Based} Vaccine against TLR3 and TLR8. An appropriate association between immune receptor molecules and the antigen molecule is essential to activate an immune responsiveness [95]. HADDOCK has been used to perform the molecular docking analyses of the MEV with human immune receptors TLR3 and TLR8. TLR3 and TLR8 can efficiently induce the immune response after virus recognition $[33,34]$. The molecular docking analyses showed effective binding interactions between MEV and TLR3/TLR8. The binding scores of MEV-TLR3 and MEV-TLR8 were observed as $-293.90 \mathrm{kcal} /$ $\mathrm{mol}$ and $-283.20 \mathrm{kcal} / \mathrm{mol}$, respectively. It was observed that MEV generated 11 hydrogen bonds within the range of $3.00 \AA$ with TLR3. MEV-interacting amino acids with hydrogen bonding to TLR3 are shown in green-colored stick representation, while similarly, TLR3 amino acids interacting through hydrogen bonding with MEV are shown in redcolored stick representation (Figure 8). 


\begin{abstract}
GIINTLQKYYCRVRGGRCAVLSCLPKEEQIGKCSTRG RKCCRRKKEAAAKGSVGFNIDYAAYLLEDEFTPFAAY HVGEIPVAYAAYLSEARQHLKAAYLVKPSFYVYAAYLV GLMWLSYAAYAGDSGFAAYAAYLSPRWYFYYAAYSSP DDQIGYAAYWTAGAAAYYAAYCNDPFLGVYAAYITDA VDCALAAYSTQDLFLPFAAYQLTPTWRVYAAYVLPFN DGVYAAYYQDVNCTEVGPGPGTLNGLWLDDVVYCPR GPGPGDLGDELGTDPYEDFQGPGPGVLLFLAFVVFLL VTLGPGPGLACFVLAAVYRINWIGPGPGCLLQFAYAN RNRFLYGPGPGAVYRINWITGGIAIAGPGPGQIGYYRR ATRRIRGGGPGPGGTWLTYTGAIKLDDKGPGPGATK AYNVTQAFGRRGGPGPGGDAALALLLLDRLNQGPGP GQSLLIVNNATNVVIKGPGPGINITRFQTLLALHRS
\end{abstract}

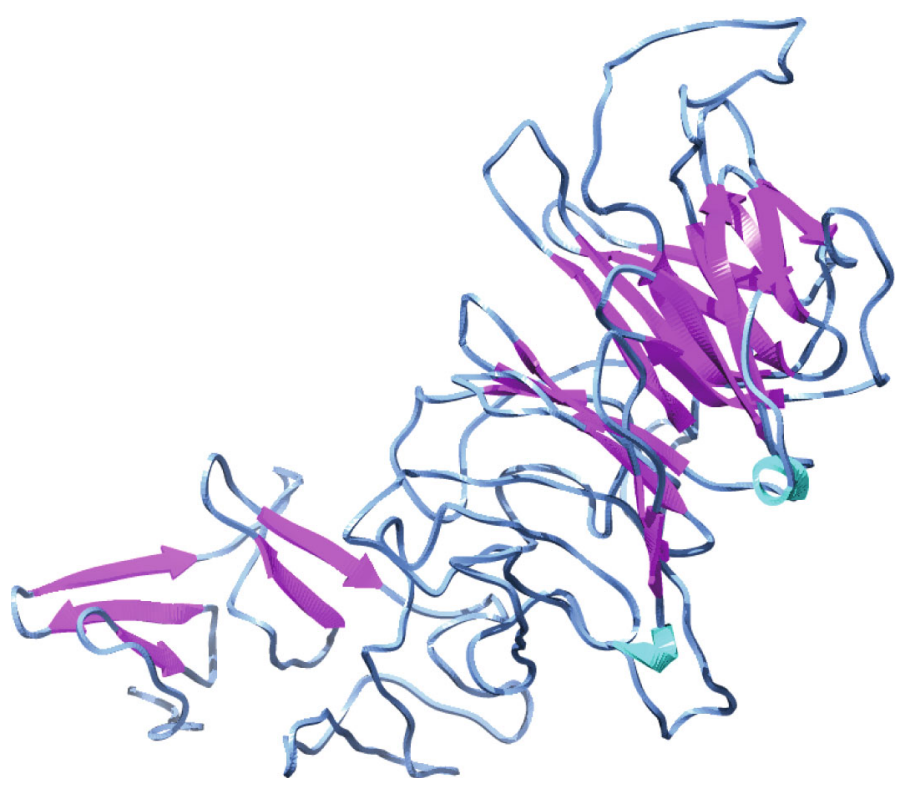

(b) (a)

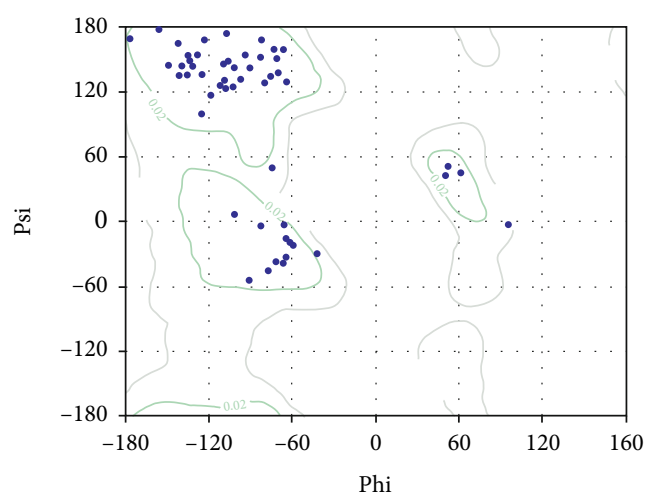

(c)

Figure 7: Sequence (a) elaborating the linkers (AAY, GPGPG, and EAAAK with purple, blue, and red color, respectively) Brown color adjuvant is also mentioned. MEV 3D structure is displayed (b); purple color indicates beta-sheets cyan color for loops, and the rest of blue color indicates turns in MEV. The Ramachandran plot evaluation of MEV is also elaborated (c).

It was observed that MEV made 9 hydrogen bond interactions within the range of $3.00 \AA$ with TLR8. Similar to TLR3, MEV-interacting amino acids with hydrogen bonding to TLR8 are shown in green-colored stick representation, while TLR8 amino acids interacting through hydrogen bonding with MEV are shown in red-colored stick representation (Figure 9).

\section{Discussion}

The need of dealing with coronaviruses has been increased since its recent breakout affecting millions of human lives. This SARS-CoV-2 viral outbreak became an emergency in different regions of the world [96]. As an immediate response, numerous efforts have been made to design the peptide-based vaccine against SARS-CoV-2. Peptide inhibitors are of great interest to develop vaccines $[97,98]$. The peptide targets are more superior than traditional ligandbased drugs including less toxicity, fewer side-effects, and their ultrafast action. Immunoinformatics methodologies are helping researchers by reducing the workload of laboratory trials; additionally, these approaches are less timeconsuming and cost-efficient than traditional approaches [99-101]. Since the last decade, there has been much progress in in silico drug designing [102]. Numerous biological complications are being solved by the implementation of different bioinformatics approaches $[80,102,103]$.

The potential CTL epitopes have been predicted for nonstructural protein (PDB: 6LU7) of SARS-CoV-2. The molecular docking tools are applied to analyze MHC-1 and ligandbinding affinities for the selected peptides [104]. Other evidences like C-terminal cleavage affinities also validate the binding affinity of peptide-MHC-I complexes. In this study, eight peptides were reported as the potential targets with effective MHC-I protein (HLA-B) interactions. Based on global energy scores, four peptides were selected having maximum binding affinities and antigenicity, increasing the probability of the potential vaccine targets for the observed residues to be a promising target. Surface accessibility and surface flexibility, as well as hydrophobicity and antigenicity, 


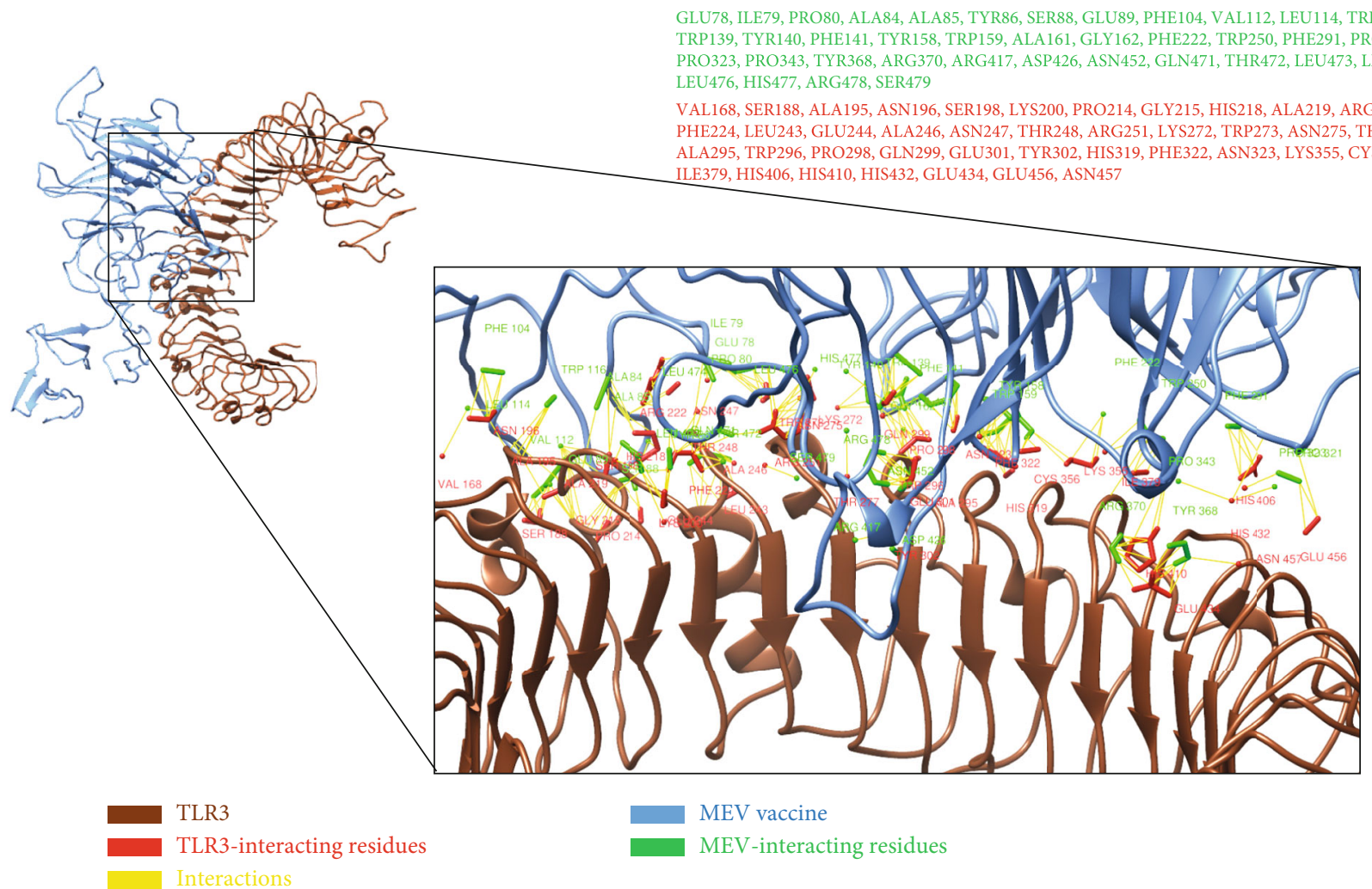

FIgURE 8: All interacting residues from MEV are shown in green color, and the rest of all red residues are TLR3-interacting residues.

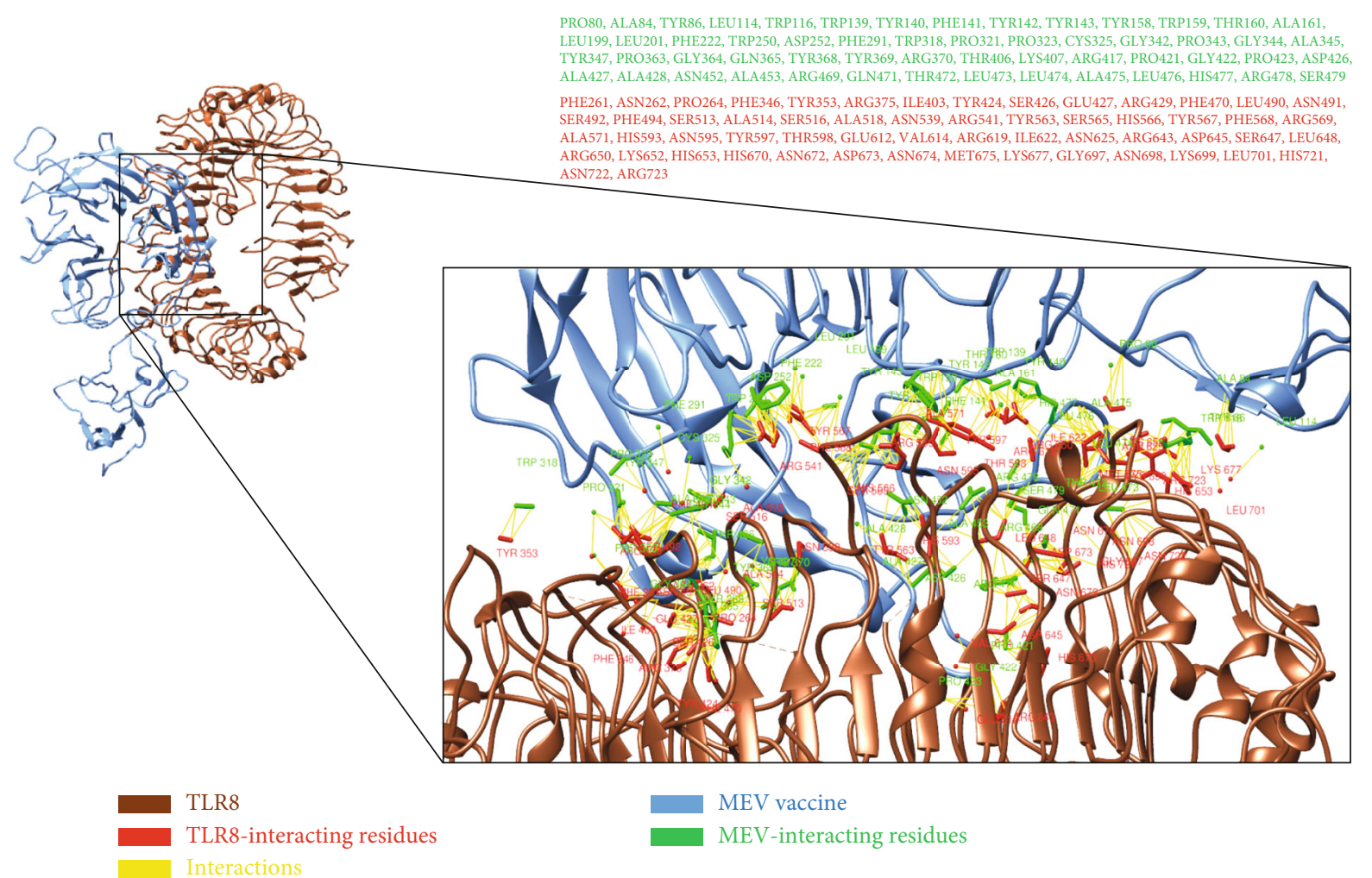

FIGURE 9: All interacting residues from MEV shown in green color and residues of TLR8 interacting residues in red color. 
for SARS-CoV-2 nonstructural protein were calculated and cross-verified using the IEDB server [105]. Based on an extensive literature review, it was observed that the selected peptides were not reported against SARS-CoV-2. The predicted peptides were modeled through PEP-FOLD3 server and docked to MHC-1 using PatchDock and further refined with FireDock. PyMOL and UCSF Chimera 1.11 were used to analyze the interactions of the docked complexes [46].

The $S$-value is a scoring function based upon the affinity of the ligand with the receptor [59]. The compounds having higher $S$-value with lower values of RMSD can be developed as potential inhibitors for a target protein [106]. For further evaluation, the binding energy of these selected hits were identified. The binding affinity showed the polar interaction of the hits with the binding site of receptor, and the value observed between 5 and $15 \mathrm{kcal} / \mathrm{mol}$ is considered a strong interaction among the ligands and the receptor [107, 108]. The molecular docking was also carried out using AutoDock and AutoDock Vina $[109,110]$.

Multiepitope vaccine construct revealed effective binding affinities against TLR3 and TLR8. The construct contains multiple epitopes from replicase, NSp1, N, E, M, and S coronavirus proteins. Various studies have been conducted by using immunoinformatics approach leading to efficient results [111-115].

\section{Conclusion}

The aim of our work was to identify the effective peptidebased inhibitors against SARS-CoV-2 nonstructural protein (PDB: 6LU7), which plays an important role in viral genome replication. Epitopes were designed, and then molecular docking was performed against MHC-I; interactional analyses of the selected docked complexes were carried out. In conclusion, four CTL epitopes (GTDLEGNFY, TVNVLAWLY, GSVGFNIDY, and QTFSVLACY) and four FDA-scrutinized compounds indicated potential targets as a peptide vaccine and potential biomolecule against deadly SARS-CoV-2, respectively. On the other hand, a multiepitope vaccine was also designed using different epitopes of coronavirus proteins joined by linkers and led by an adjuvant, which can be a possible potential MEV against coronavirus. Our findings can be a step towards the development of a peptide-based vaccine or natural compound drug target against SARS-CoV-2 which is one of the trending issues nowadays due to the exponentially increasing death rate all over the world.
Abbreviations
CPE: $\quad$ Cytopathic effects
SARS-CoV: Severe acute respiratory syndrome coronavirus
MERS-CoV: Middle East respiratory syndrome coronavirus
RBD: $\quad$ Receptor-binding domain
MHC: $\quad$ Major histocompatibility complex
HLA: Human leukocyte antigen
MOE: Molecular Operating Environment
CTL: $\quad$ Cytotoxic T-lymphocyte
pI: $\quad$ Isoelectric point

ADMET: Absorption distribution metabolism elimination toxicity.

\section{Conflicts of Interest}

Authors have no conflicts of interest form anyone.

\section{Authors' Contributions}

MW, AH, AR, MQA, AU, MS, HNA, AM, RR, and DR performed the computational analyses, RAT analyzed the data, and SAS conceived the project, analyzed the results, and drafted the manuscript.

\section{Acknowledgments}

Authors are thankful to Mr. Jonathan Javid for the help in molecular docking analyses.

\section{Supplementary Materials}

Supplementary 1. Effect of SARS (severe acute respiratory syndrome) in 2002.

Supplementary 2. CTL epitopes and physiochemical properties of epitopes.

Supplementary 3. Physiochemical properties and population coverage analysis.

Supplementary 4. Multiple sequence alignment.

Supplementary 5. FDA ligands selected by molecular docking studies and their properties evaluated by MOE, AutoDock, AutoDock Vina, and admetSAR.

\section{References}

[1] S. A. Stohlman and D. R. Hinton, "Viral induced demyelination," Brain Pathology, vol. 11, no. 1, pp. 92-106, 2001.

[2] J. S. Guy, J. J. Breslin, B. Breuhaus, S. Vivrette, and L. G. Smith, "Characterization of a coronavirus isolated from a diarrheic foal," Journal of Clinical Microbiology, vol. 38, no. 12, pp. 4523-4526, 2000.

[3] J. S. Peiris, C. M. Chu, V. C. Cheng et al., "Clinical progression and viral load in a community outbreak of coronavirusassociated SARS pneumonia: a prospective study," Lancet, vol. 361, no. 9371, pp. 1767-1772, 2003.

[4] B. E. Martina, B. L. Haagmans, T. Kuiken et al., "Virology: SARS virus infection of cats and ferrets," Nature Structural \& Molecular Biology, vol. 425, p. 915, 2003.

[5] E. J. Snijder, P. J. Bredenbeek, J. C. Dobbe et al., "Unique and conserved features of genome and proteome of SARS-coronavirus, an early split-off from the coronavirus group 2 lineage," Journal of Molecular Biology, vol. 331, no. 5, pp. 9911004, 2003.

[6] W M H C W M, H.a.H.C.s.B.n.o.t.C.P.E.S.i.O.C.A.oJanuary 2020. https://www.wuhan.gov.cn/front/web/showDetail/ 2019123108989.

[7] L. E. Gralinski and D. M. Vineet, "Return of the Coronavirus: 2019-nCoV," Viruses 12.2, vol. 135, 2020.

[8] P. Wu, X. Hao, E. H. Lau et al., "Real-time tentative assessment of the epidemiological characteristics of novel 
coronavirus infections in Wuhan, China," Eurosurveillance, vol. 25, no. 3, p. 2000044, 2020.

[9] "Eurosurveillance Editorial Team. Note from the editors: World Health Organization declares novel coronavirus (2019-nCoV) sixth public health emergency of international concern," Eurosurveillance, vol. 25, no. 5, p. 200131e, 2020.

[10] L. Riva, S. Yuan, X. Yin et al., "Discovery of SARS-CoV-2 antiviral drugs through large-scale compound repurposing," Nature, vol. 586, no. 7827, pp. 113-119, 2020.

[11] N. Imai, I. Dorigatti, A. Cori, S. Riley, and N. M. Ferguson, Estimating the potential total number of novel coronavirus (2019-nCoV) cases in Wuhan City, ChinaJanuary 2020. https://www.imperial.ac.uk/mrcglobal-infectious-diseaseanalysis/news-wuhan-coronavirus/.

[12] D. K Chu, Y. Pan, S. M. Cheng et al., "Molecular diagnosis of a novel coronavirus (2019-nCoV) causing an outbreak of pneumonia," Clinical chemistry, vol. 66, no. 4, pp. 549-555, 2020.

[13] W. Ji, W. Wang, X. Zhao, J. Zai, and X. Li, "Homologous recombination within the spike glycoprotein of the newly identi? ed coronavirus may boost cross-species transmission from snake to human," Journal of Medical Virology, vol. 92, pp. 433-440, 2020.

[14] D. Robertson and X. Jiang, $n$ CoV's relationship to bat coronaviruses and recombination signals no snakes January 2020. https://virological.org/t/ncovs-relationship-to-batcoronaviruses-recombination-signals-nosnakes/331.

[15] S. K. Lau, P. C. Woo, K. S. Li et al., "Severe acute respiratory syndrome coronavirus-like virus in Chinese horseshoe bats," Proceedings of the National Academy of Sciences of the United States of America, vol. 102, no. 39, pp. 14040-14045, 2005.

[16] V. D. Menachery, B. L. Yount Jr., A. C. Sims et al., "SARS-like WIV1-CoV poised for human emergence," Proceedings of the National Academy of Sciences of the United States of America, vol. 113, no. 11, pp. 3048-3053, 2016.

[17] N. Wang, S. Y. Li, X. L. Yang et al., "Serological evidence of bat SARS-related coronavirus infection in humans, China," Virologica Sinica, vol. 33, no. 1, pp. 104-107, 2018.

[18] P. L. Quan, C. Firth, C. Street et al., "Identification of a severe acute respiratory syndrome coronavirus-like virus in a leafnosed bat in Nigeria," mBio, vol. 1, no. 4, pp. e00208e00210, 2010.

[19] E. I. Azhar, S. A. El-Kafrawy, S. A. Farraj et al., "Evidence for camel-to-human transmission of MERS coronavirus," New England Journal of Medicine, vol. 370, no. 26, pp. 24992505, 2014.

[20] A. R. Fehr, R. Channappanavar, and S. Perlman, "Middle East respiratory syndrome: emergence of a pathogenic human coronavirus," Annual Review of Medicine, vol. 68, no. 1, pp. 387-399, 2017.

[21] A. Assiri, J. A. Al-Tawfiq, A. A. Al-Rabeeah et al., "Epidemiological, demographic, and clinical characteristics of 47 cases of Middle East respiratory syndrome coronavirus disease from Saudi Arabia: A descriptive study," Lancet Infectious Diseases, vol. 13, no. 9, pp. 752-761, 2013.

[22] A. Rahman and A. Sarkar, "Risk factors for fatal Middle East respiratory syndrome coronavirus infections in Saudi Arabia: Analysis of the WHO Line List, 2013-2018," American Journal of Public Health, vol. 109, no. 9, pp. 1288-1293, 2019.

[23] D. R. Beniac, A. Andonov, E. Grudeski, and T. F. Booth, "Architecture of the SARS coronavirus prefusion spike,"
Nature Structural \& Molecular Biology, vol. 13, no. 8, pp. 751-752, 2006.

[24] M. Waqas, A. Haider, M. Sufyan, S. Siraj, and S. A. Sehgal, "Determine the potential epitope based peptide vaccine against novel SARS-CoV-2 targeting structural proteins using immunoinformatics approaches," Frontiers in Molecular Biosciences, vol. 7, 2020.

[25] P. K. C. Cheng, D. A. Wong, L. K. L. Tong et al., "Viral shedding patterns of coronavirus in patients with probable severe acute respiratory syndrome," Lancet, vol. 363, no. 9422, pp. 1699-1700, 2004.

[26] P. Zhou, X. L. Yang, X. G. Wang et al., Discovery of a novel coronavirus associated with the recent pneumonia outbreak in humans and its potential bat origin, BioRxiv, 2020.

[27] V. D. Menachery, R. L. Graham, and R. S. Baric, "Jumping species-a mechanism for coronavirus persistence and survival," Current Opinion in Virology, vol. 23, pp. 1-7, 2017.

[28] M. M. Becker, R. L. Graham, E. F. Donaldson et al., "Synthetic recombinant bat SARS-like coronavirus is infectious in cultured cells and in mice," Proceedings of the National Academy of Sciences, vol. 105, no. 50, pp. 19944-19949, 2008.

[29] L. Zhao, B. K. Jha, A. Wu et al., "Antagonism of the interferon-induced OAS-RNase L pathway by murine coronavirus ns2 protein is required for virus replication and liver pathology," Cell Host \& Microbe, vol. 11, no. 6, pp. 607-616, 2012.

[30] M. Barcena, G. T. Oostergetel, W. Bartelink et al., "Cryo-electron tomography of mouse hepatitis virus: insights into the structure of the coronavirion," Proceedings of the National Academy of Sciences of the United States of America, vol. 106, no. 2, pp. 582-587, 2009.

[31] C. K. Chang, S. C. Sue, T. H. Yu et al., "Modular organization of SARS coronavirus nucleocapsid protein," Journal of Biomedical Science, vol. 13, no. 1, pp. 59-72, 2006.

[32] World Health Organization, "Novel Coronavirus - China," https://www.who.int/csr/don/12-january-2020-novelcoronavirus-china/en/. 12 January 2020.

[33] E. Y. So and T. Ouchi, "The application of toll like receptors for cancer therapy," International Journal of Biological Sciences, vol. 6, no. 7, pp. 675-681, 2010.

[34] S. C. Higgins and K. H. Mills, "TLR, NLR agonists, and other immune modulators as infectious disease vaccine adjuvants," Current Infectious Disease Reports, vol. 12, no. 1, pp. 4-12, 2010.

[35] S. K. Burley, H. M. Berman, C. Bhikadiya et al., "RCSB Protein Data Bank: biological macromolecular structures enabling research and education in fundamental biology, biomedicine, biotechnology and energy," Nucleic Acids Research, vol. 47, no. D1, pp. D464-D474, 2019.

[36] M. R. Wilkins, E. Gasteiger, A. Bairoch et al., "Protein identification and analysis tools in the ExPASy server," Methods in Molecular Biology, vol. 112, pp. 531-552, 1998.

[37] E. W. Sayers, M. Cavanaugh, K. Clark, J. Ostell, K. D. Pruitt, and I. Karsch-Mizrachi, "GenBank," Nucleic Acids Research, vol. 47, no. D1, pp. D94-D99, 2019.

[38] E. W. Sayers, M. Cavanaugh, K. Clark, J. Ostell, K. D. Pruitt, and I. Karsch-Mizrachi, "GenBank," Nucleic Acids Research, vol. 48, no. D1, pp. D84-D86, 2020.

[39] F. Sievers and D. G. Higgins, "Clustal omega," Current Protocols in Bioinformatics, vol. 48, no. 1, pp. 3.13.1-3.13.16, 2014.

[40] F. Sievers and D. G. Higgins, "Clustal omega for making accurate alignments of many protein sequences," Protein Science, vol. 27, no. 1, pp. 135-145, 2018. 
[41] G. E. Crooks, G. Hon, J. M. Chandonia, and S. E. Brenner, "WebLogo: a sequence logo generator," Genome Research, vol. 14, no. 6, pp. 1188-1190, 2004.

[42] D. T. Nair, K. Singh, Z. Siddiqui, B. P. Nayak, K. V. S. Rao, and D. M. Salunke, "Epitope recognition by diverse antibodies suggests conformational convergence in an antibody response," Journal of Immunology, vol. 168, no. 5, pp. 23712382, 2002.

[43] J. M. R. Parker, D. Guo, and R. S. Hodges, "New hydrophilicity scale derived from high-performance liquidchromatography peptide retention data - correlation of predicted surface residues with antigenicity and X-ray-derived accessible sites," Biochemistry, vol. 25, no. 19, pp. 54255432, 2002.

[44] P. A. Karplus and G. E. Schulz, "Prediction of chain flexibility in proteins," Naturwissenschaften, vol. 72, no. 4, pp. 212-213, 1985.

[45] N. Alexander, N. Woetzel, and J. Meiler, "bcl::Cluster : A method for clustering biological molecules coupled with visualization in the Pymol Molecular Graphics System," in 2011 IEEE 1st International Conference on Computational Advances in Bio and Medical Sciences (ICCABS), vol. 2011, pp. 13-18, Orlando, FL, USA, 2011.

[46] E. F. Pettersen, T. D. Goddard, C. C. Huang et al., "UCSF chimera - a visualization system for exploratory research and analysis," Journal of Computational Chemistry, vol. 25, no. 13, pp. 1605-1612, 2004.

[47] E. A. Emini, J. V. Hughes, D. S. Perlow, and J. Boger, "Induction of hepatitis A virus-neutralizing antibody by a virusspecific synthetic peptide," Journal of Virology, vol. 55, no. 3, pp. 836-839, 1985.

[48] Z. Nain, F. Abdulla, M. M. Rahman et al., "Proteome-wide screening for designing a multi-epitope vaccine against emerging pathogenElizabethkingia anophelisusing immunoinformatic approaches," Journal of Biomolecular Structure \& Dynamics, vol. 38, no. 16, pp. 4850-4867, 2020.

[49] X. M. Wen, S.i.W.C.r.N.C.P., and another suspected January 2020, http://china.qianlong.com/2020/0121/3600877.shtml.

[50] R. Vita, S. Mahajan, J. A. Overton et al., "The Immune Epitope Database (IEDB): 2018 update," Nucleic Acids Research, vol. 47, no. D1, pp. D339-D343, 2019.

[51] A. Lamiable, P. Thévenet, J. Rey, M. Vavrusa, P. Derreumaux, and P. Tufféry, "PEP-FOLD3: faster de novo structure prediction for linear peptides in solution and in complex," Nucleic Acids Research, vol. 44, no. W1, pp. W449-W454, 2016.

[52] J. Maupetit, P. Tuffery, and P. Derreumaux, "A coarsegrained protein force field for folding and structure prediction," Proteins-Structure Function and Bioinformatics, vol. 69, no. 2, pp. 394-408, 2007.

[53] P.-T. Huang, P.-H. Lo, C.-H. Wang, C.-T. Pang, and K.L. Lou, "PPDock-Portal Patch Dock: a web server for drug virtual screen and visualizing the docking structure by GP and X-score," Acta Crystallographica Section A Foundations of Crystallography, vol. 66, no. a1, pp. S233-S234, 2010.

[54] E. Mashiach, D. Schneidman-Duhovny, N. Andrusier, R. Nussinov, and H. J. Wolfson, "FireDock: a web server for fast interaction refinement in molecular docking," Nucleic Acids Research, vol. 36, no. Web Server, pp. W229-W232, 2008.

[55] N. Andrusier, R. Nussinov, and H. J. Wolfson, "FireDock: fast interaction refinement in molecular docking," Proteins-Struc- ture Function and Bioinformatics, vol. 69, no. 1, pp. 139-159, 2007.

[56] C. L. Kingsford, B. Chazelle, and M. Singh, "Solving and analyzing side-chain positioning problems using linear and integer programming," Bioinformatics, vol. 21, no. 7, pp. 10281039, 2005.

[57] C. B. Palatnik-de-Sousa, I. d. S. Soares, and D. S. Rosa, "Editorial: epitope discovery and synthetic vaccine design," Frontiers in Immunology, vol. 9, no. 826, 2018.

[58] M. Tahir ul Qamar, S. Saleem, U. A. Ashfaq, A. Bari, F. Anwar, and S. Alqahtani, "Epitope-based peptide vaccine design and target site depiction against Middle East respiratory syndrome coronavirus: an immune-informatics study," Journal of Translational Medicine, vol. 17, no. 1, p. 362, 2019.

[59] S. Vilar, G. Cozza, and S. Moro, "Medicinal chemistry and the Molecular Operating Environment (MOE): application of QSAR and molecular docking to drug discovery," Current Topics in Medicinal Chemistry, vol. 8, no. 18, pp. 15551572, 2008.

[60] S. Dallakyan and A. J. Olson, "Small-molecule library screening by docking with PyRx," Methods in Molecular Biology, vol. 1263, pp. 243-250, 2015.

[61] J. Shen, F. Cheng, Y. Xu, W. Li, and Y. Tang, "Estimation of ADME properties with substructure pattern recognition," Journal of Chemical Information and Modeling, vol. 50, no. 6, pp. 1034-1041, 2010.

[62] T. Khan, S. Dixit, R. Ahmad et al., "Molecular docking, PASS analysis, bioactivity score prediction, synthesis, characterization and biological activity evaluation of a functionalized 2butanone thiosemicarbazone ligand and its complexes," Journal of Chemical Biology, vol. 10, no. 3, pp. 91-104, 2017.

[63] A. Ayati, M. Falahati, H. Irannejad, and S. Emami, "Synthesis, in vitro antifungal evaluation and in silico study of 3-azolyl4-chromanone phenylhydrazones," DARU Journal of Pharmaceutical Sciences, vol. 20, no. 1, article 46, 2012.

[64] A. C. Wallace, R. A. Laskowski, and J. M. Thornton, "Ligplot - a program to generate schematic diagrams of protein ligand interactions," Protein Engineering, vol. 8, no. 2, pp. 127-134, 1995.

[65] R. Leinonen, F. G. Diez, D. Binns, W. Fleischmann, R. Lopez, and R. Apweiler, "UniProt archive," Bioinformatics, vol. 20, no. 17, pp. 3236-3237, 2004.

[66] C. H. Wu, R. Apweiler, A. Bairoch et al., "The Universal Protein Resource (UniProt): an expanding universe of protein information," Nucleic Acids Research, vol. 34, no. 90001, pp. D187-D191, 2006.

[67] M. V. Larsen, A. Lelic, R. Parsons et al., "Identification of CD8+ T cell epitopes in the West Nile virus polyprotein by reverse-immunology using NetCTL," PLoS One, vol. 5, no. 9, article e12697, 2010.

[68] N. J. Schisler and J. D. Palmer, "The IDB and IEDB: intron sequence and evolution databases," Nucleic Acids Research, vol. 28, no. 1, pp. 181-184, 2000.

[69] J. Ponomarenko, N. Papangelopoulos, D. M. Zajonc, B. Peters, A. Sette, and P. E. Bourne, "IEDB-3D: structural data within the immune epitope database," Nucleic Acids Research, vol. 39, no. Database, pp. D1164-D1170, 2010.

[70] J. Peng and J. Xu, "RaptorX: exploiting structure information for protein alignment by statistical inference," Proteins, vol. 79, Suppl 10, pp. 161-171, 2011.

[71] P. L. Kastritis, J. P. Rodrigues, and A. M. Bonvin, "HADDOCK(2P2I): a biophysical model for predicting the binding 
affinity of protein-protein interaction inhibitors," Journal of Chemical Information and Modeling, vol. 54, no. 3, pp. 826836, 2014.

[72] M. van Dijk, K. M. Visscher, P. L. Kastritis, and A. M. J. J. Bonvin, "Solvated protein-DNA docking using HADDOCK," Journal of Biomolecular NMR, vol. 56, no. 1, pp. 51-63, 2013.

[73] H. Lu, C. W. Stratton, and Y. W. Tang, "Outbreak of pneumonia of unknown etiology in Wuhan, China: the mystery and the miracle," Journal of Medical Virology, vol. 92, no. 4, pp. 401-402, 2020.

[74] WHO, Coronavirus2019. https://www.who.int/health-topics/ coronavirus.

[75] N. J. D. MacLachlan and E. J. Dubovi, Fenner's veterinary virology, Elsevier, 2017.

[76] A. H. de Wilde, E. J. Snijder, M. Kikkert, and M. J. van Hemert, "Host factors in coronavirus replication," in Roles of Host Gene and Non-Coding Rna Expression in Virus Infection, vol. 419, pp. 1-42, 2017.

[77] M. G. Douglas, J. F. Kocher, T. Scobey, R. S. Baric, and A. S. Cockrell, "Adaptive evolution influences the infectious dose of MERS-CoV necessary to achieve severe respiratory disease," Virology, vol. 517, pp. 98-107, 2018.

[78] T. C. Vilela Rodrigues, A. K. Jaiswal, A. de Sarom et al., "Reverse vaccinology and subtractive genomics reveal new therapeutic targets againstMycoplasma pneumoniae: a causative agent of pneumonia," Royal Society Open Science, vol. 6, no. 7, article 190907, 2019.

[79] M. Davies and D. Flower, "Harnessing bioinformatics to discover new vaccines," Drug Discovery Today, vol. 12, no. 9-10, pp. 389-395, 2007.

[80] R. A. Tahir, H. Wu, M. A. Rizwan, T. H. Jafar, S. Saleem, and S. A. Sehgal, "Immunoinformatics and molecular docking studies reveal potential epitope-based peptide vaccine against DENV-NS3 protein," Journal of Theoretical Biology, vol. 459, pp. 162-170, 2018.

[81] Z. Shen, G. Wang, Y. Yang et al., "A conserved virulence region within alphacoronavirus nsp1," The Journal of Biological Chemistry, vol. 294, no. 37, pp. 13606-13618, 2019.

[82] L. Guo, S. D. Sharma, J. D. Debes et al., “The hepatitis C viral nonstructural protein $5 \mathrm{~A}$ stabilizes growth-regulatory human transcripts," Nucleic Acids Research, vol. 48, no. 3, p. 1599, 2020.

[83] S. J. Goebel, T. B. Miller, C. J. Bennett, K. A. Bernard, and P. S. Masters, "A hypervariable region within the 3 ' cis-acting element of the murine coronavirus genome is nonessential for RNA synthesis but affects pathogenesis," Journal of Virology, vol. 81, no. 3, pp. 1274-1287, 2007.

[84] B. Abere, N. Samarina, S. Gramolelli et al., "Kaposi's sarcoma-associated herpesvirus nonstructural membrane protein pK15 recruits the class II phosphatidylinositol 3kinase PI3K-C2 $\alpha$ to activate productive viral replication," Journal of Virology, vol. 92, no. 17, 2018.

[85] Q. Chen, L. Zhang, H. Chen, L. Xie, and T. Wei, "Nonstructural protein Pns4 of rice dwarf virus is essential for viral infection in its insect vector," Virology Journal, vol. 12, no. 1, p. 211, 2015.

[86] Q. Chen, H. Chen, D. Jia, Q. Mao, L. Xei, and T. Wei, “Nonstructural protein Pns12 of rice dwarf virus is a principal regulator for viral replication and infection in its insect vector," Virus Research, vol. 210, pp. 54-61, 2015.

[87] C. Xu, L. Feng, P. Chen et al., "Viperin inhibits classical swine fever virus replication by interacting with viral nonstructural
5A protein," Journal of Medical Virology, vol. 92, no. 2, pp. 149-160, 2019.

[88] I. Dimitrov, L. Naneva, I. Doytchinova, and I. Bangov, "AllergenFP: allergenicity prediction by descriptor fingerprints," Bioinformatics, vol. 30, no. 6, pp. 846-851, 2014.

[89] J. Ponomarenko, H. H. Bui, W. Li et al., "ElliPro: a new structure-based tool for the prediction of antibody epitopes," BMC Bioinformatics, vol. 9, no. 1, p. 514, 2008.

[90] J. J. Irwin and B. K. Shoichet, "ZINC-a free database of commercially available compounds for virtual screening," Journal of Chemical Information and Modeling, vol. 45, no. 1, pp. 177-182, 2005.

[91] M. S. Duthie, H. P. Windish, C. B. Fox, and S. G. Reed, "Use of defined TLR ligands as adjuvants within human vaccines," Immunological Reviews, vol. 239, no. 1, pp. 178-196, 2011.

[92] G. G. Zom, S. Khan, D. V. Filippov, and F. Ossendorp, "TLR ligand-peptide conjugate vaccines: toward clinical application," Advances in immunology, vol. 114, pp. 177201, 2012.

[93] R. B. Russell, M. A. S. Saqi, R. A. Sayle, P. A. Bates, and M. J. E. Sternberg, "Recognition of analogous and homologous protein folds: analysis of sequence and structure conservation ${ }^{1,}$ Journal of Molecular Biology, vol. 269, no. 3, pp. 423-439, 1997.

[94] Y. Zhang and J. Skolnick, "TM-align: a protein structure alignment algorithm based on the TM-score," Nucleic Acids Research, vol. 33, no. 7, pp. 2302-2309, 2005.

[95] K. Zaks, M. Jordan, A. Guth et al., "Efficient immunization and cross-priming by vaccine adjuvants containing TLR3 or TLR9 agonists complexed to cationic liposomes," The Journal of Immunology, vol. 176, no. 12, pp. 7335-7345, 2006.

[96] C. S. Mcclain, "A new look at an old disease - smallpox and biotechnology," Perspectives in Biology and Medicine, vol. 38, no. 4, pp. 624-639, 1995.

[97] M. F. Chew, K. S. Poh, and C. L. Poh, "Peptides as therapeutic agents for dengue virus," International Journal of Medical Sciences, vol. 14, no. 13, pp. 1342-1359, 2017.

[98] M. Usman Mirza, S. Rafique, A. Ali et al., “Towards peptide vaccines against Zika virus: immunoinformatics combined with molecular dynamics simulations to predict antigenic epitopes of Zika viral proteins," Scientific Reports, vol. 6, no. 1, article 37313, 2016.

[99] P. Vanhee, A. M. van der Sloot, E. Verschueren, L. Serrano, F. Rousseau, and J. Schymkowitz, "Computational design of peptide ligands," Trends in Biotechnology, vol. 29, no. 5, pp. 231-239, 2011.

[100] M. Heurich, Z. Altintas, and I. E. Tothill, "Computational design of peptide ligands for ochratoxin A," Toxins, vol. 5, no. 6, pp. 1202-1218, 2013.

[101] D. R. Xu, H. Bian, J. Cai et al., "Computational design of peptide ligands to target the intermolecular interaction between viral envelope protein and pediatric receptor," Computational Biology and Chemistry, vol. 69, pp. 120-125, 2017.

[102] S. A. Sehgal, "Pharmacoinformatics, adaptive evolution, and elucidation of six novel compounds for schizophrenia treatment by targeting DAOA (G72) isoforms," Biomed Research International, vol. 2017, 19 pages, 2017.

[103] S. A. Sehgal, N. A. Khattak, and A. Mir, "Structural, phylogenetic and docking studies of D-amino acid oxidase activator (DAOA), a candidate schizophrenia gene," Theoretical Biology and Medical Modelling, vol. 10, no. 1, p. 3, 2013. 
[104] A. Alam, S. Ali, S. Ahamad, M. Z. Malik, and R. Ishrat, "From ZikV genome to vaccine: in silico approach for the epitopebased peptide vaccine against Zika virus envelope glycoprotein," Immunology, vol. 149, no. 4, pp. 386-399, 2016.

[105] F. Sieker, A. May, and M. Zacharias, "Predicting affinity and specificity of antigenic peptide binding to major histocompatibility class I molecules," Current Protein \& Peptide Science, vol. 10, no. 3, pp. 286-296, 2009.

[106] M. Tahir ul Q, S. Kiran, U. A. Ashfaq et al., "Discovery of novel dengue NS2B/NS3 protease inhibitors using pharmacophore modeling and molecular docking based virtual screening of the ZINC database," International Journal of Pharmacology, vol. 12, no. 6, pp. 621-632, 2016.

[107] V. Cicaloni, A. Trezza, F. Pettini, and O. Spiga, “Applications of in silico methods for design and development of drugs targeting protein-protein interactions," Current Topics in Medicinal Chemistry, vol. 19, no. 7, pp. 534-554, 2019.

[108] A. A. Ezat and W. M. Elshemey, "A comparative study of the efficiency of HCV NS3/4A protease drugs against different HCV genotypes using in silico approaches," Life Sciences, vol. 217, pp. 176-184, 2019.

[109] O. Trott and A. J. Olson, “AutoDock Vina: improving the speed and accuracy of docking with a new scoring function, efficient optimization, and multithreading," Journal of Computational Chemistry, vol. 31, no. 2, pp. 455-461, 2010.

[110] T. F. Vieira and S. F. Sousa, "Comparing AutoDock and Vina in ligand/decoy discrimination for virtual screening," Applied Sciences, vol. 9, no. 21, p. 4538, 2019.

[111] M. I. Abdelmageed, A. H. Abdelmoneim, M. I. Mustafa et al., "Design of a multiepitope-based peptide vaccine against the $\mathrm{E}$ protein of human COVID-19: an immunoinformatics approach," BioMed Research International, vol. 2020, 12 pages, 2020.

[112] P. Kalita, A. K. Padhi, K. Y. J. Zhang, and T. Tripathi, “Design of a peptide-based subunit vaccine against novel coronavirus SARS-CoV-2," Microbial Pathogenesis, vol. 145, p. 104236, 2020.

[113] A. R. Oany, T. Pervin, and A. Emran, "Design of an epitopebased peptide vaccine against spike protein of human coronavirus: an in silico approach," Drug Design, Development and Therapy, vol. 8, pp. 1139-1149, 2014.

[114] M. Bhattacharya, A. R. Sharma, P. Patra et al., "Development of epitope-based peptide vaccine against novel coronavirus 2019 (SARS-COV-2): immunoinformatics approach," Journal of Medical Virology, vol. 92, no. 6, pp. 618-631, 2020.

[115] M. Enayatkhani, M. Hasaniazad, S. Faezi et al., "Reverse vaccinology approach to design a novel multi-epitope vaccine candidate against COVID-19: anin silicostudy," Journal of Biomolecular Structure \& Dynamics, vol. 39, pp. 1-16, 2020. 